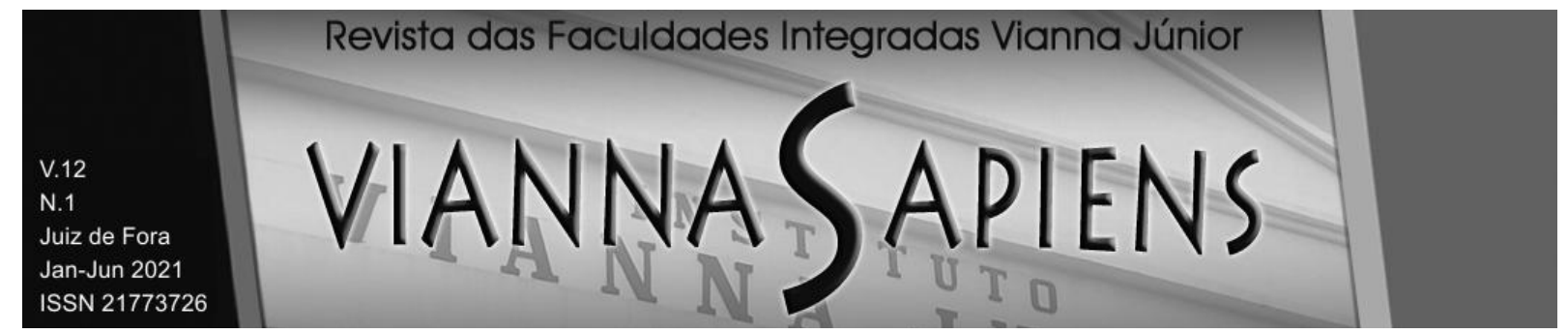

\title{
O impacto da crise pelo Covid-19 nas micro e pequenas empresas DOI: 10.31994/rvs.v12i1.707
}

\author{
Dusan Schreiber ${ }^{1}$ \\ Margareth Aparecida Moraes ${ }^{2}$ \\ Ligia Stasiak ${ }^{3}$
}

\section{RESUMO}

A crise que afeta o Brasil decorrente da pandemia relacionada ao Covid-19, tem grande reflexo em todos os segmentos empresariais. Com o objetivo de identificar os impactos financeiros e econômicos causados pela pandemia de COVID-19 nas micro e pequenas empresas localizadas na região metropolitana de Porto Alegre RS foram analisadas 21 empresas tributadas pelo Simples Nacional. Os aspectos metodológicos utilizados consistem em pesquisa bibliográfica acerca dos assuntos pertinentes ao tema, fornecendo subsídios para a coleta de dados empíricos da pesquisa, que pode ser considerada exploratória e descritiva, suportadas por análises quantitativas, estudo de casos múltiplos com dados de natureza documental. Diante dos resultados obtidos foi possível constatar que dezesseis das vinte e uma empresas analisadas já sofreram com redução em seus faturamentos nos primeiros meses da pandemia, e onze empresas realizaram redução do quadro de funcionários através de demissões, apenas quatro utilizaram-se das reduções e suspensões disponibilizadas pelo governo.

\footnotetext{
${ }^{1}$ Doutor em Administração. Universidade FEEVALE. Email: dusan@feevale.br. Número ORCID: 0000-0003-4258-4780

${ }^{2}$ Mestrado em Qualidade Ambiental. Universidade FEEVALE. Email: margarethm@feevale.br Número ORCID: 0000-0002-5892-9221

${ }^{3}$ Graduação em Ciências Contábeis. Universidade FEEVALE

Email: ligia stasiak@hotmail.com - Número ORCID: 0000-0002-3748-3486
} 


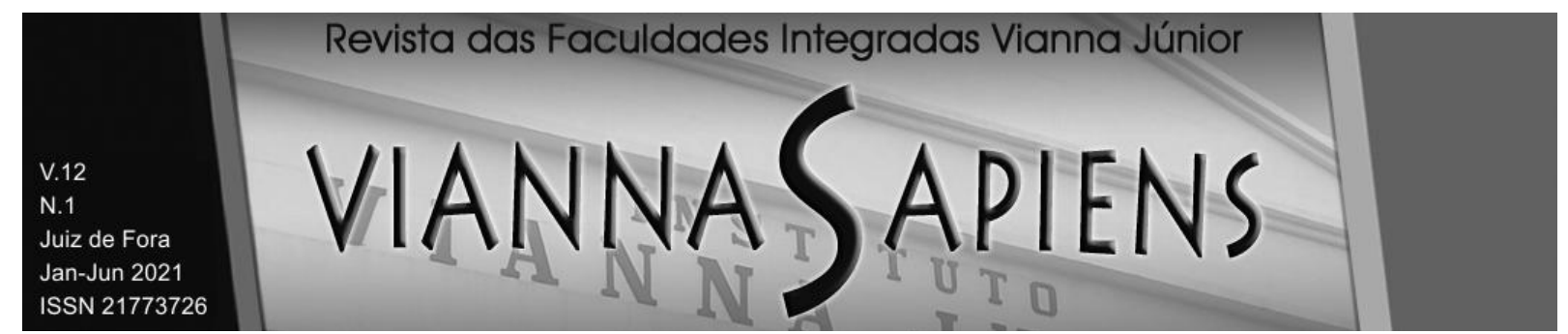

\title{
PALAVRAS-CHAVE: MICRO E PEQUENA. PANDEMIA. COVID-19.
}

The impact of the Covid-19 crisis on micro and small companies

\begin{abstract}
The crisis that affects Brazil due to the Covid-19 related pandemic has a great impact on all business segments. In order to identify the financial and economic impacts caused by the COVID-19 pandemic on micro and small companies located in the metropolitan region of Porto Alegre - RS, 21 companies taxed by Simples Nacional were analyzed. The methodological aspects used consist of a bibliographic review on the subjects relevant to the theme, providing subsidies for the collection of empirical data of the research, which can be considered exploratory and descriptive, supported by quantitative analyzes, multiple case studies with data of a documentary nature. In view of the results obtained, it was possible to verify that sixteen of the twenty-one companies analyzed had already suffered from a reduction in their earnings in the first months of the pandemic, and eleven companies reduced the number of employees through layoffs, only four used reductions and suspensions made available by the government.
\end{abstract}

KEYWORDS: MICRO AND SMALL. PANDEMIC. COVID-19.

\section{INTRODUÇÃO}

Em meados do ano de 2019, iniciou-se a disseminação global de um novo vírus, oriundo da China. O novo tipo de coronavírus, nomeado de Covid-19, tem uma capacidade de disseminação rápida e é mais grave para idosos e pessoas com 


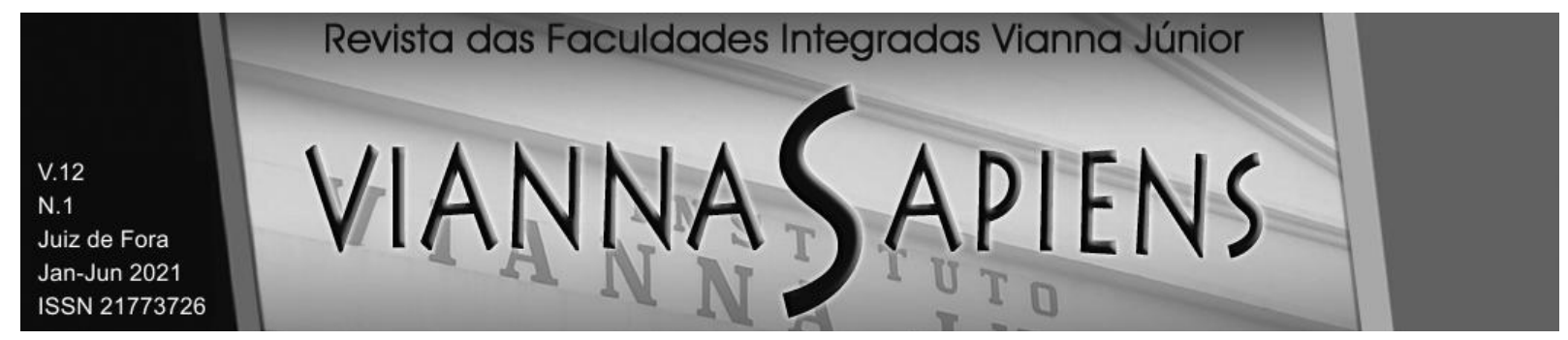

problemas de saúde, causando nas mesmas a necessidade de internação e tratamento intensivo, resultando assim no esgotamento da capacidade de atendimento da rede de saúde. A rápida disseminação do vírus e o aumento da utilização dos leitos em hospitais levou às autoridades públicas a tomarem medidas para conter o mesmo, destacando-se como principal medida paliativa, o isolamento social, o qual é recomendado por diversos infectologistas (BRASIL, 2020; FREITAS; NAPIMOGA; DONALISIO, 2020).

$\mathrm{O}$ isolamento social tem sido variado conforme a necessidade local, com medidas sendo adotadas de acordo com a quantidade de casos, leitos disponíveis, tipo populacional e demais fatores que possam influenciar na disseminação do vírus. Com o isolamento, as atividades econômicas e sociais que constituem em aglomeração de pessoas ficaram proibidas, o que impacta diretamente na economia, seja local ou global, com a redução do consumo de bens e serviços pela população, o que acarreta em redução no faturamento, redução na arrecadação pública de tributos e, consequentemente, na redução de empregos (BRASIL, 2020; FREITAS; NAPIMOGA; DONALISIO, 2020; SEBRAE, 2020).

As referidas medidas governamentais, para conter o contágio por Covid-19, por meio do isolamento social, acarretou a suspensão de atividades principalmente em setores econômicos como prestação de serviços e comércio varejista, representados, principalmente, por empresas de porte micro ou pequeno (SEBRAE, 2020). As micro e pequenas empresas possuem grande importância para o funcionamento e o desenvolvimento da economia nacional, evidenciado pelo aumento da quantidade de micro e pequenas empresas em funcionamento nas últimas duas décadas, impulsionando a geração dos postos de trabalho, principalmente nos momentos de crise econômica. Nos mais diversos países, em razão da relevância do papel desempenhado pelas micro e pequenas empresas no desenvolvimento e crescimento econômico local, são criadas políticas públicas voltadas para auxílio e benefício das mesmas, para que possam continuar em operação (PESSÔA; COSTA; MACCARI, 2016). 


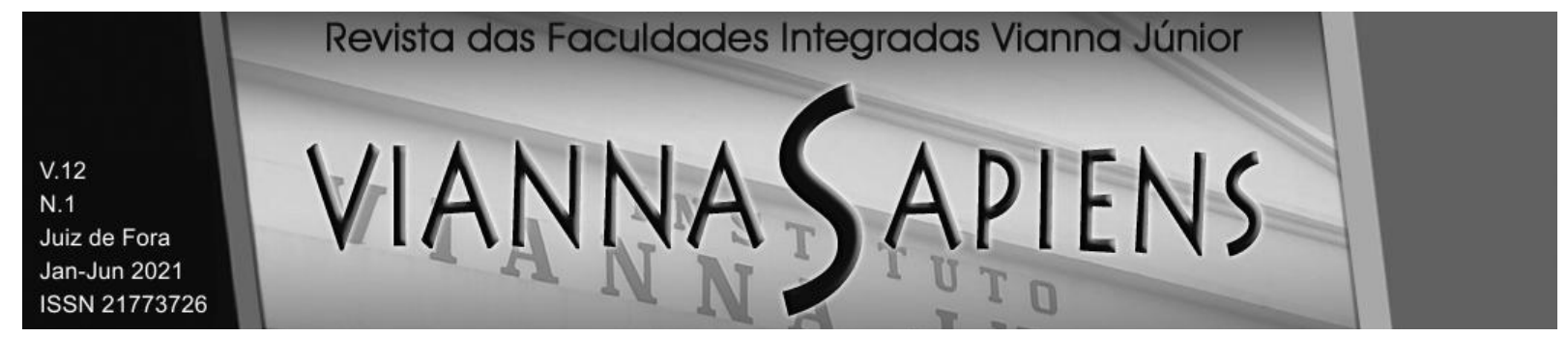

Em razão da importância das micro e pequenas empresas para a economia nacional, no ano de 2006, através da Lei Complementar no 123 de 14 de dezembro de 2006, foi criado o Estatuto Nacional da Microempresa e da Empresa de Pequeno Porte, também conhecido como Lei Geral da Micro e Pequena Empresa. O Estatuto Nacional da Microempresa e da Empresa de Pequeno Porte foi instituído com o objetivo de regulamentar a redação determinada no artigo 179 da Constituição Federal, o qual garante tratamento diferenciado para as pequenas empresas, para assim incentivá-las ao crescimento, sendo que o referido tratamento pode ser no âmbito tributário, previdenciário, jurídico, entre outros (COSTA; LEANDRO, 2016).

No que diz respeito à geração de novos empregos e índices de contratações formais, é possível afirmar que são os pequenos negócios que mantém a economia brasileira em movimento. De janeiro até agosto de 2019, no Brasil, as micro e pequenas empresas criaram aproximadamente 541,7 mil empregos, quantidade 15 vezes maior do que a registrada pelas médias e grandes empresas. As contratações foram lideradas pelo setor de prestação de serviços, especialmente do ramo imobiliário e de ensino. A região Sudeste do país liderou a geração de empregos pelas micro e pequenas empresas neste mesmo período (SEBRAE, 2019).

Este artigo tem como objetivo principal, por meio de uma pesquisa descritiva e exploratória, com a estratégia de estudo de casos múltiplos, identificar os impactos financeiros e econômicos causados pela pandemia de COVID-19 nas micro e pequenas empresas localizadas na região metropolitana de Porto Alegre - RS, para evidenciar quais empresas participantes do estudo utilizaram-se das medidas governamentais disponibilizadas para enfrentamento do referido período temporal, bem como identificar qual das atividades desenvolvidas pelas micro e pequenas empresas foi mais afetado.

Desta forma, a presente pesquisa está dividida em cinco segmentos, sendo o primeiro esta introdução, seguida pela fundamentação teórica, esta subdividida em quatro partes, na qual estão especificadas o que são as micro e pequenas empresas, sua representatividade no cenário econômico nacional, as formas de tributação às quais estão sujeitas, a pandemia de COVID-19 no Brasil e no mundo, 


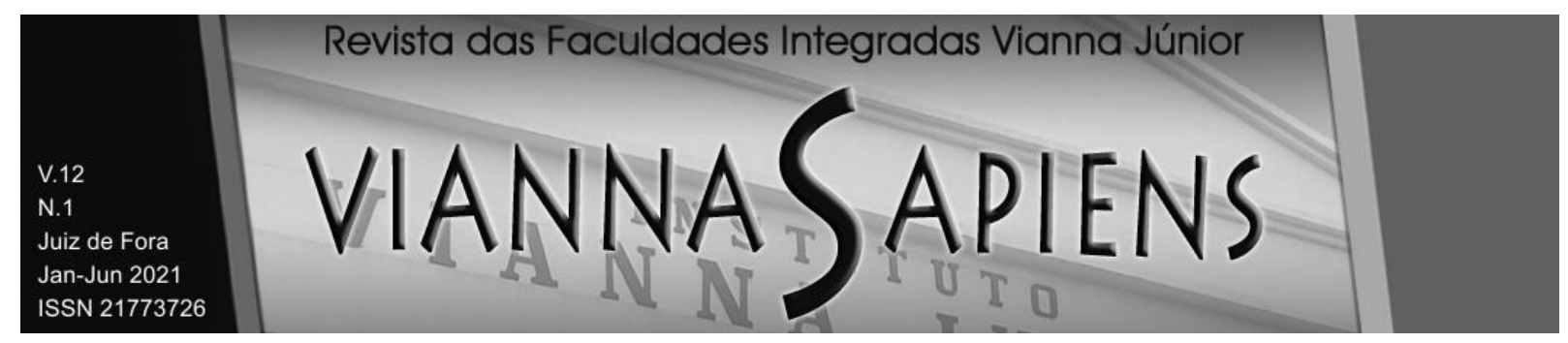

e, as medidas criadas pelos governos para auxílio às empresas enfrentarem o impacto econômico e financeiro causado pela crise de COVID-19. O terceiro capítulo aborda a metodologia utilizada para alcançar os objetivos propostos. Na sequência apresenta-se a análise dos dados coletados, bem como as considerações finais com sugestões de novas pesquisas, bem como o conjunto de referências utilizado como base para o estudo.

\section{PANDEMIA DO COVID-19 E SEU IMPACTO NA ECONOMIA}

As operações empresariais no Brasil, notadamente as de organizações de portes micro e pequeno, já estavam sendo desafiadas a permanecer em funcionamento, em virtude da crise econômica no período de 2014 a 2017 (BARBOSA FILHO, 2017) quando, no início de 2020, se depararam com um desafio muito maior - o da restrição ao seu funcionamento, em decorrência do contágio do novo coronavírus, intitulado de Covid-19.

Oriundo da China, da cidade de Wuhan, o novo coronavírus demonstrou uma capacidade impressionante em se disseminar e de contaminar pessoas, em nível global, de forma muito rápida e com nível de letalidade próximo de 7\%, levando a óbito principalmente as pessoas nas faixas etárias mais elevadas ou com histórico de algum tipo de comorbidade, como diabetes, hipertensão, obesidade, entre outros. Atuando essencialmente sobre o sistema respiratório da pessoa infectada, o Covid19 reduz a sua capacidade de oxigenação, o que nas pessoas do referido grupo de risco, implica a demanda por tratamento intensivo e ocupação de respiradores mecânicos, por períodos temporais que podem exceder 15 dias, o que, na maioria das vezes, representa o risco de esgotamento da capacidade operacional do sistema de saúde (BRASIL, 2020).

A combinação nefasta da capacidade de disseminação rápida com a igualmente rápida evolução do quadro das pessoas contaminadas, para demandar o atendimento do sistema de saúde, por vezes, de tratamento intensivo, devido ao 


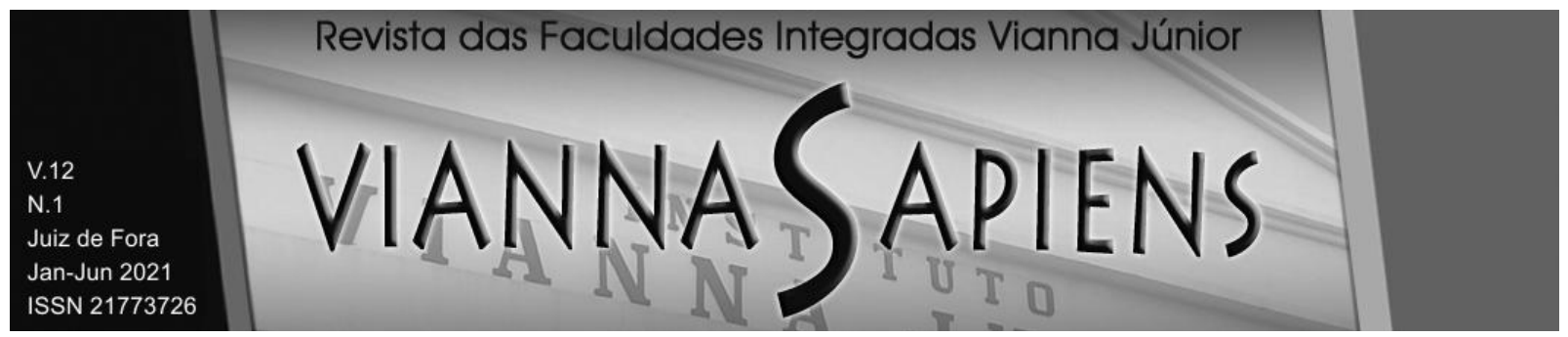

agravamento do estado, com risco de óbito, exigiu de autoridades públicas, da totalidade dos países, em nível global, a adoção de medidas para reduzir a velocidade da contaminação e evitar o colapso do sistema público de saúde. Dentre as referidas medidas destacou-se a de isolamento social, que foi adotado em níveis variados de intensidade nos países afetados pela pandemia do Covid-19 (FREITAS; NAPIMOGA; DONALISIO, 2020).

$\mathrm{O}$ isolamento social é defendido pelos pesquisadores de infectologia e epidemiologia, de forma praticamente unânime, em nível mundial, como a medida mais efetiva, para resguardar os sistemas públicos de saúde, do possível colapso, em casos de ocorrência de picos de contágio. A ocorrência do pico de contágio representa o cenário mais grave para o sistema público de saúde, devido à demanda, no mesmo período temporal, por leitos em hospitais e pelo tratamento intensivo nas UTI's. Este risco é potencial, pois todos os sistemas de saúde foram projetados para funcionar dentro dos parâmetros de certa normalidade, ou seja, para atender as demandas da população conforme o seu perfil e histórico já conhecido de necessidades de tratamentos de saúde. Nesta perspectiva, quaisquer situações atípicas, que vem a apresentar demandas mais intensas por determinadas unidades hospitalares, podem causar colapso do sistema de saúde de qualquer país, independentemente do seu nível de desenvolvimento econômico (BRASIL, 2020; FREITAS; NAPIMOGA; DONALISIO, 2020).

Desta forma, o isolamento social não pode ser considerado apenas como recomendado, mas, como obrigatório, para as autoridades públicas de qualquer país, com noções mínimas de responsabilidade. Por esse motivo, por mais impactante para a população de todos os países afetados, as referidas medidas de isolamento social foram instituídas e sua operacionalização e adoção fiscalizada pelos órgãos de segurança pública, com previsão de penalidades legais, em casos de descumprimento. O processo de adoção das medidas de isolamento social, no entanto, não ocorreu de forma imediata, em todos os países, iniciando-se na região do epicentro, cidade Wuhan, da China, depois na Itália, que representou o foco de contágio no continente europeu, os demais países europeus, à medida que o 


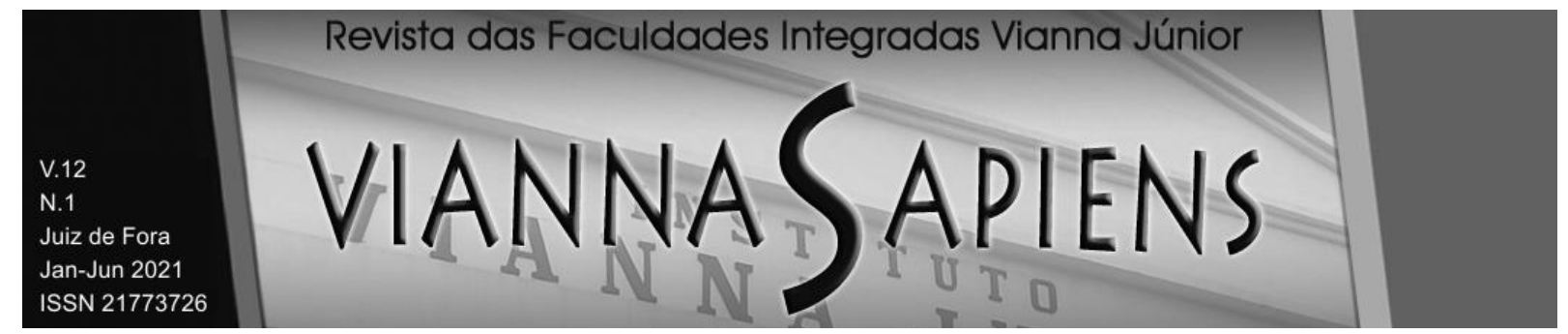

contágio do Covid-19 foi sendo confirmado e, por fim, nos continentes americano, africano, Oriente Médio e nos países da Oceania (BRASIL, 2020).

$\mathrm{O}$ isolamento social significa determinar a proibição de todas as atividades, econômicas e sociais, que provocam a aglomeração de pessoas. Trata-se, portanto, de uma medida que contrasta radicalmente com a lógica estruturante do sistema capitalista, que é construído sobre a ideia de aumento contínuo e sustentado de volume comercializado, seja de bens ou de serviços, para um número, cada vez maior, de consumidores, estimulando o comportamento do consumo, por vezes, coletivo (SEBRAE, 2020). Nesta perspectiva a interação social representa, cada vez mais, uma janela de oportunidade ímpar, para promover o consumo, alavancar as vendas e, por conseguinte, gerar empregos, renda e alternativa de investimento (BOTELHO; GUISSONI, 2016).

O sistema de capitalismo moderno é estimulado e fomentado pelo empreendedorismo, pela inovação, pela interação social, pela colaboração, compartilhamento, ... que se apoia na ideia de coletividade, de pessoas com vida social pujante, consumindo, nutrindo desejos de consumo, sonhando com oportunidades de crescimento pessoal, sendo reconhecidas por pessoas do seu grupo social específico, planejando constituir famílias, financiar projetos pessoais ou profissionais, serem ou, no mínimo, almejarem a felicidade, seguindo os ditames preconizados do sistema econômico e social vigente (BOTELHO; GUISSONI, 2016).

Com o isolamento social muitos dos projetos pessoais e profissionais foram abortados, não apenas no curto prazo, mas, dependendo do tipo do sonho ou do projeto, no prazo médio ou longo. Com o obrigatório encerramento das atividades consideradas não essenciais pelos agentes governamentais, por períodos de tempo que, em muitos casos, excederam 45 dias, maioria das operações empresariais, que já operavam no limite de sua capacidade financeira, devido ao longo período da maior crise econômica que o país já passou, no período de 2014 a 2017, que não tinham o caixa suficiente para honrar os compromissos com seus fornecedores, 


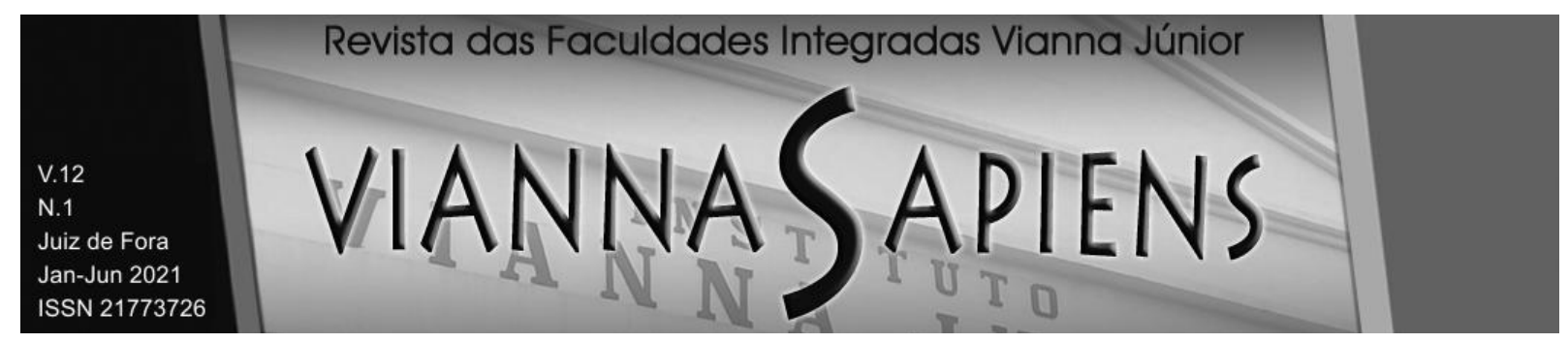

funcionários, entre outros, foram obrigados a encerrar a operação (BARBOSA FILHO, 2017).

Já aqueles empreendedores que tinham reservas financeiras e conseguiram negociar com seus funcionários para concessão de férias, lay-off, banco de horas, redução de carga horária e consequente remuneração, se depararam com um novo desafio - reabertura de seus negócios, com restrição de funcionamento a um percentual determinado da capacidade instalada, instituída legalmente, por agentes governamentais, com o intuito de evitar a nova onda de contágio pelo Covid-19. Vale destacar que a reabertura de negócios, com e referida restrição a um percentual determinado, da capacidade instalada, não é exclusividade do Brasil, sendo adotado pela grande maioria dos países, ao redor do planeta (BRASIL, 2020; BOTELHO; GUISSONI, 2016).

A restrição da atividade econômica, a um determinado percentual da capacidade instalada, foi concebida seguindo as recomendações dos especialistas em saúde pública, para, como já comentado antes, evitar as aglomerações de pessoas, sejam eles colaboradores ou consumidores. Novamente, como já foi dito, a referida lógica contrasta com os ditames subjacentes ao modelo de funcionamento da maioria das organizações, sejam do setor da indústria, comércio ou de prestação de serviços, que visa a otimização de espaço físico ocupado (que tem, normalmente, um custo elevado), de pessoas alocadas no fluxo operacional, bem como na utilização máxima (ou ótima) da infraestrutura, representada pelo conjunto de ativos disponibilizados para a atividade econômica especifica (SLACK, 2018).

Conforme preconizam os inúmeros trabalhos acadêmicos, manuais ou simples "passo a passo" do empreendedorismo, voltados para orientar como proceder na elaboração do plano de negócios, as estruturas organizacionais são cuidadosamente desenhadas para otimizar os recursos alocados à operação. Com outras palavras, é possível afirmar que, dificilmente, nas organizações em operação, em qualquer tipo de atividade econômica, tem colaboradores "sobrando", tem consumidores "em excesso" ou os espaços físicos são sempre subutilizados (DORNELAS, 2018). 


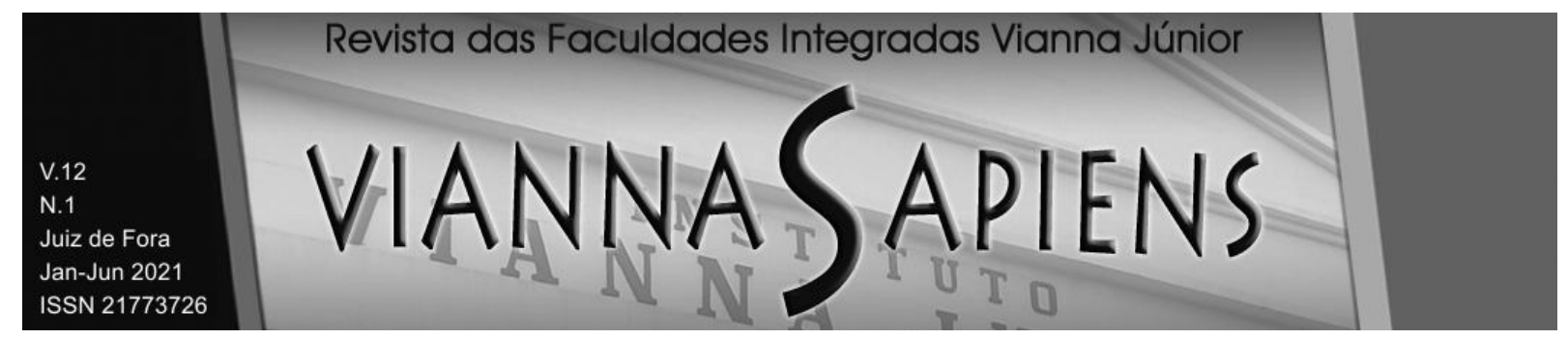

Além disso, as estruturas organizacionais e, principalmente, operacionais, de algumas operações fabris, baseiam-se na utilização intensiva de pessoas, em linhas de produção que remontam ao período da primeira revolução industrial e ao arranjo produtivo taylorista fordista, como, por exemplo, na fabricação de calçados, frigoríficos, entre outros. Neste tipo de organização, com utilização intensiva de mão de obra, alocada em linhas de produção, com uma pessoa do lado de outra, com atividades de reduzido nível de complexidade, simples, padronizada e repetitiva, com imposição de tempo de produção por peça, de produtividade máxima, emerge o desafio de reorganizar a operação, em modelo de possa atender as novas imposições legais, para evitar aglomeração de pessoas (e consequentemente reduzir o risco de contágio) e, ao mesmo tempo, assegurar a produtividade e lucratividade mínima (SLACK, 2018).

O referido desafio extrapola a mera revisão do lay-out industrial, de redefinir as tarefas das pessoas, a forma de coordenar o fluxo operacional, pois as margens de contribuição calculadas ex-ante, baseadas no fluxo operacional tradicional de produção, normalmente já bastante reduzidas, como é comum em atividades industriais que operam no referido modelo de produção, baseado no uso intensivo de mão de obra, terão que ser revistas, frente a esta nova realidade. As mudanças exigidas na forma de produzir deverão impactar, com toda a certeza, sobre as estruturas de custos, com pressão para o aumento de preços, para preservar a operação, via remuneração minimamente adequada de todos os fatores de produção (BRUNI, 2018).

Vindo ao encontro com as dificuldades enfrentadas pelas empresas em razão do isolamento social estabelecido globalmente, o governo Federal homologou algumas medidas legais para auxiliar as organizações, principalmente as micro e pequenas empresas, no enfrentamento da crise financeira e econômica que se assolou em meio à pandemia global de COVID-19. 


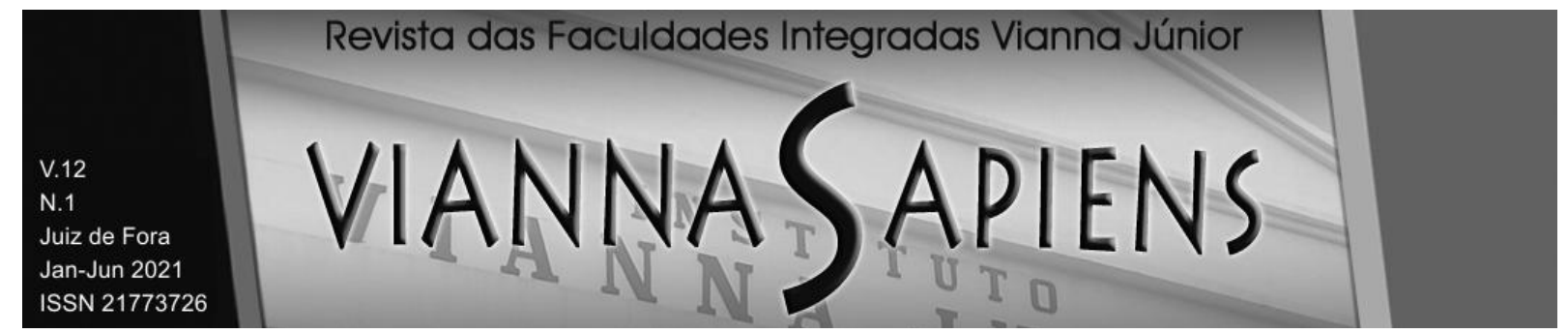

\section{MEDIDAS GOVERNAMENTAIS PARA ENFRENTAMENTO DA CRISE ECONÔMICA E FINANCEIRA DURANTE A PANDEMIA}

Devido à crise econômica e financeira instaurada em meio à pandemia de COVID-19 o governo brasileiro viu-se obrigado a editar medidas para auxiliar as empresas no enfrentamento deste período adverso. Os governos Federais, Estaduais e Municipais editaram legislações conforme suas disponibilidades para tentar cooperar com um auxílio financeiro para as empresas com sede no Brasil, principalmente para as micro e pequenas empresas, as quais geralmente não possuem uma boa gestão do seu capital de giro, sendo assim, geralmente não possuem reservas para eventuais emergências (SOBRAL; CARDOSO; SANCHES, 2017).

Iniciando pelas medidas adotadas pelo governo Federal, vale destacar a Medida Provisória no 927 de 22 de março de 2020, que modificou diversos critérios na área trabalhista, permitindo então a antecipação de férias individuais ou coletivas, de feriados, utilização de banco de horas, teletrabalho, diferimento no recolhimento do FGTS - Fundo de Garantia do Tempo de Serviço. Essas mudanças foram permitidas em razão do isolamento social, orientado pela OMS - Organização Mundial da Saúde e considerado imprescindível para reduzir a circulação do vírus, assim reduzindo o número de infectados (CORREIO BRAZILIENSE, 2020).

Muitas empresas tiveram que manter-se de portas fechadas, sendo impedidas de desenvolver suas atividades econômicas por algum período. Pode se citar, a título de exemplo, as atividades de comércio, por exemplo, na cidade de Porto Alegre - RS, que através do Decreto no 20.534 de 31 de março de 2020, todas as atividades não essenciais ficaram impedidas de operar. As empresas que permaneceram impedidas de continuar suas operações, estiveram amparadas legalmente para realizar antecipação de férias e a compensação das horas transcorridas nas licenças remuneradas através de banco de horas, permitidas pela MP no 927/2020. Algumas empresas, de prestação de serviços, que não puderam 


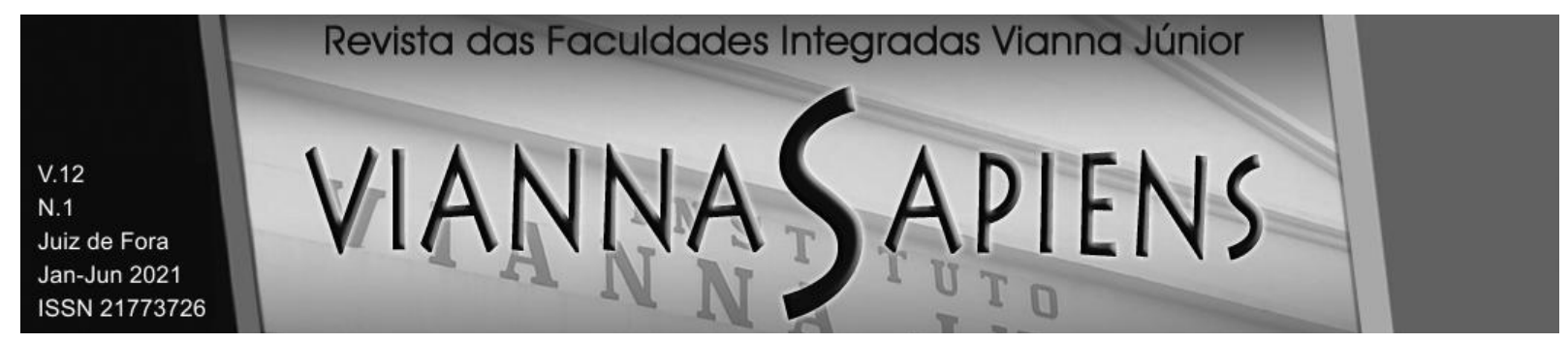

suspender suas atividades totalmente, se utilizaram do teletrabalho para atender suas demandas remotamente, quando possível.

Com o intuito de proporcionar um alívio financeiro para as empresas enquadradas neste regime de tributação, o Comitê Gestor do Simples Nacional homologou a Resolução no 154 de 03 de abril de 2020, que prorrogou o pagamento dos tributos federais, devidos pelas empresas tributadas pelo Simples Nacional com vencimento em abril, maio e junho para os meses de outubro, novembro e dezembro. A Resolução № 154/2020 também prorrogou o pagamento dos tributos estaduais e municipais, devidos pelas empresas tributadas pelo Simples Nacional, com vencimento em abril, maio e junho para os meses de julho, agosto e setembro, respectivamente. Desta forma cada empresa podia organizar suas finanças e, caso não tivesse disponível o valor integral do DAS, pôde quitar parte dos tributos no primeiro vencimento e o saldo no vencimento posterior, aliviando, parcialmente, a pressão sobre seu capital de giro.

Outra medida adotada pelo governo federal foi o lançamento do Programa Emergencial de Manutenção do Emprego e Renda, através da Medida Provisória no 936 de $1^{\circ}$ de abril de 2020, cuja foi convertida na Lei no 14.020 de 6 de julho de 2020. A Lei no 14.020/2020 determina a possibilidade de suspensão ou redução de jornada do contrato de trabalho com auxílio financeiro disponibilizado aos trabalhadores, tendo como principal objetivo reduzir os impactos sociais, neste momento de calamidade pública.

Em consequência, para as empresas, ocorre uma redução nos desembolsos financeiros com a folha de pagamento. De acordo com o Ministério da Economia, com estas medidas, estima-se que 8,5 milhões de empregos serão preservados e um total de 24,5 milhões de trabalhadores receberão o benefício, representando um valor aproximado de 51,2 bilhões de reais. No entanto, ainda, de acordo com o Ministério da Economia deverá ocorrer uma redução de 15\% na renda média dos trabalhadores.

De acordo com a Lei no $14.020 / 2020$ foi facultado ao empregador celebrar com seus funcionários contratos individuais ou coletivos de suspensão ou redução 


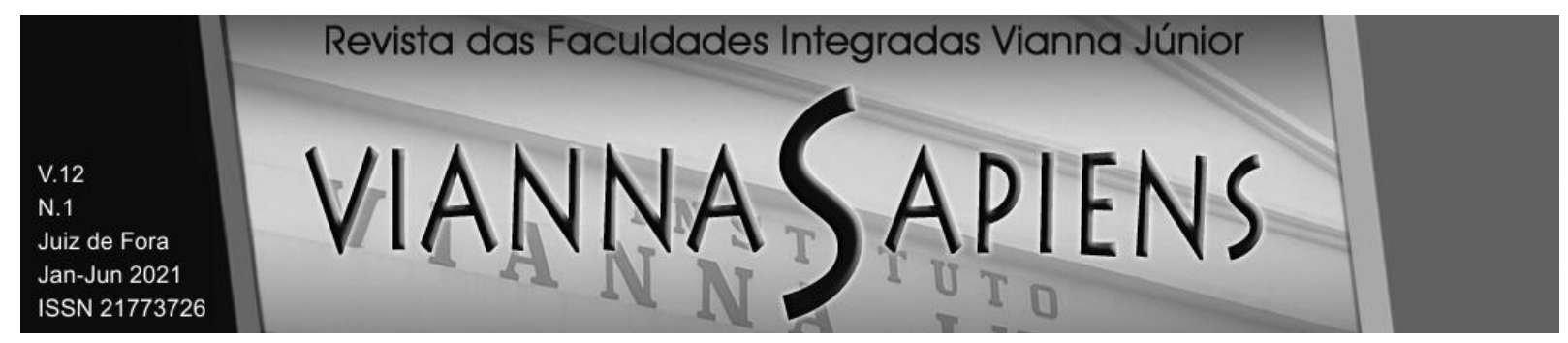

de jornada de trabalho, sendo que na suspensão, o governo se comprometeu em arcar com o pagamento mensal de um valor a esse funcionário, calculado conforme seus rendimentos anteriores e utilizando como base a forma de cálculo do atual seguro desemprego. Em contrapartida, a empresa não poderia demitir o colaborador pelo mesmo período em que esteve suspenso, ou seja, o funcionário adquire estabilidade pelo mesmo período em que esteve com o contrato suspenso junto à empresa.

Já no caso da redução de jornada de trabalho, também permitida pela Lei $\mathrm{n}$ ำ 14.020/2020, o governo subsidiou uma parte do salário, calculada de acordo com os rendimentos anteriores e utilizando como base a forma atual do cálculo do seguro desemprego, por ser redução de jornada de trabalho, o empregador custeia a outra parte do salário. As reduções permitidas são de 25\%, 50\% e 75\%. Por exemplo, o funcionário tem sua carga horária reduzida em 50\%, supondo que ele trabalhe oito horas por dia, passa a trabalhar quatro horas diárias, as quais serão custeadas pela empresa, o governo federal pagará para esse funcionário um valor para complementar sua renda, que será equivalente a $50 \%$ do valor do seguro desemprego a que ele teria direito, já que a base de cálculo utilizada para o cálculo é a mesma do atual seguro desemprego.

Anteriormente à criação das medidas trabalhistas e financeiras já citadas, com a homologação da Lei no 13.979 de 06 de fevereiro de 2020, houve também a dispensa da obrigatoriedade de execução do processo licitatório para entes governamentais realizarem a aquisição de bens e serviços que sejam necessários para o enfrentamento da emergência de saúde pública originada pela pandemia de COVID-19, tornando mais prático e fácil o acesso aos bens necessários.

Além das medidas trabalhistas e das prorrogações de vencimento de algumas competências do DAS do Simples Nacional e do FGTS, o governo federal lançou alguns programas de financiamentos e empréstimos para as micro e pequenas empresas. 


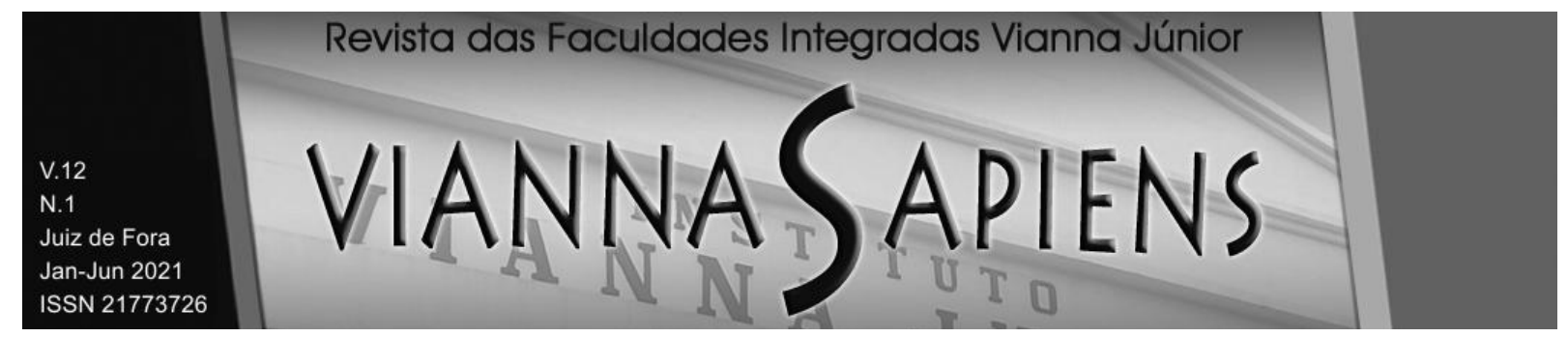

\section{PROGRAMAS FINANCEIROS DISPONIBILIZADOS PARA AS MICRO E PEQUENAS EMPRESAS}

Uma das primeiras medidas financeiras idealizadas pelo governo federal para auxiliar no combate à crise econômica instaurada pela pandemia de COVID-19 nas micro e pequenas empresas foi a redação da Medida Provisória ํo 944 de 3 de abril de 2020, a qual criou o Programa Emergencial de Suporte a Empregos. Este programa tem por finalidade a realização de empréstimos para as empresas custearem sua folha de pagamento.

Algumas empresas não puderam parar suas atividades e tiveram seu faturamento reduzido, com isso a MP № 944/2020 criou um sistema de empréstimos para pagamento da folha de salários. Podem aderir a esse programa as empresas que auferiram receita bruta no ano de 2019 entre $R \$ 360.000,00$ e $R \$$ 50.000.000,00, conforme art. $2^{\circ}$ da MP $n^{\circ}$ 944/2020, ou seja, em razão do faturamento limite para adesão ao programa, são beneficiadas também as empresas de médio e grande porte, que não são optantes pelo Simples Nacional, as quais não são objetos deste estudo.

De acordo com a MP o 944/2020, nesta modalidade, os recursos que a empresa toma como empréstimo não são depositados na conta bancária da empresa, os relatórios das folhas de pagamento são entregues à instituição financeira que deu origem ao recurso, e a própria instituição fornece a informação para que o valor seja depositado diretamente na conta do funcionário, conforme o salário devido. No entanto há uma limitação de valores, de até dois salários mínimos, ou seja, o colaborador que recebe mais que esse valor deverá solicitar a diferença para a empresa.

Com esta medida a empresa tem seis meses de carência e até trinta e seis meses para pagar o empréstimo junto à instituição financeira, com os juros fixados em 3,75\% ao ano. Ainda, a empresa que realizar adesão a este empréstimo não poderá demitir os funcionários cadastrados no contrato durante o período de 


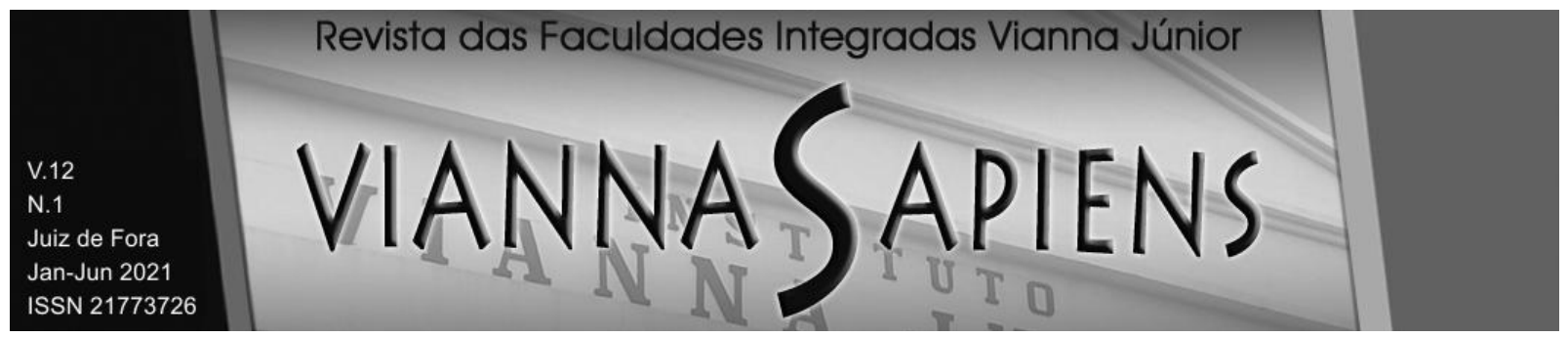

vigência do empréstimo e por dois meses após o término do contrato estipulado, criando assim estabilidade no emprego e renda dos trabalhadores (BRASIL, 2020).

Outra medida financeira criada pelo governo federal foi o Programa Nacional de Apoio às Microempresas e Empresas de Pequeno Porte - Pronampe. O Pronampe é um programa governamental destinado ao desenvolvimento das pequenas empresas, instituído pela Lei ํo 13.999 de 18 de maio de 2020 . Diferentemente do financiamento citado anteriormente, o Pronampe não está vinculado à folha de pagamento, sendo uma linha de crédito para capital de giro, investimentos, para suprir a folha de pagamento, entre outros. $O$ valor é depositado na conta da empresa e fica disponível para ser utilizado de acordo com a necessidade momentânea, porém o valor não pode ser utilizado para distribuição de lucros ou dividendos aos sócios (SEBRAE, 2020).

Neste empréstimo, os recursos não são oriundos do governo federal, sendo a própria instituição financeira responsável por firmar o contrato de financiamento que realizará com seus recursos disponíveis. Todavia os empréstimos realizados através do Pronampe estão garantidos por um depósito realizado pelo governo federal junto ao Fundo Garantidor de Operações - FGO, administrado pelo Banco do Brasil. Por ser um programa federal para auxílio emergencial no momento de pandemia, as instituições financeiras estão dispensadas de solicitar alguns documentos para liberação do crédito, tornando a operação mais rápida e eficaz (SEBRAE, 2020).

Conforme a Lei ํㅜ 13.999/2020 o crédito concedido para as Microempresas e Empresas de Pequeno Porte através do Pronampe, será de até 30\% do faturamento auferido no ano de 2019, para as empresas que foram constituídas no decorrer de 2019 o crédito será de até $50 \%$ de seu capital social ou $30 \%$ de seu faturamento médio auferido em 2019, o que for mais vantajoso para a empresa. Apesar de os recursos não serem disponibilizados pelo governo, o mesmo estipulou prazo máximo e taxa de juros máxima para realização do empréstimo, de acordo com o art. $3^{\circ}$ da Lei no 13.999/2020, visto que, no atual cenário de pandemia as empresas estão passando por dificuldades financeiras e econômicas e um empréstimo facilitado 


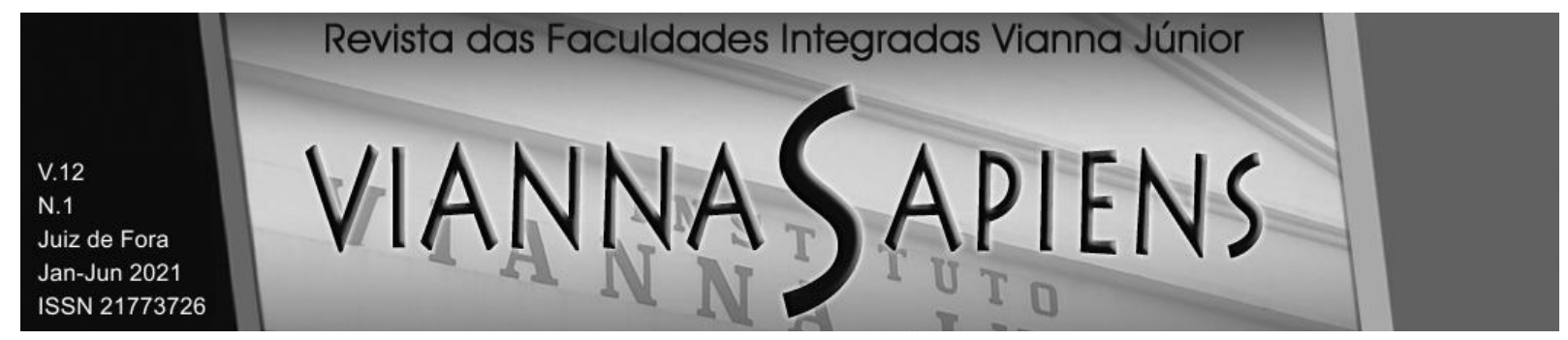

pode auxiliar no desenvolvimento e fortalecimento dos microempresários neste momento.

Por ser um programa especial as empresas que aderirem ao Pronampe também estão sujeitas a algumas regras, como, por exemplo o instituído no art. $2^{\circ} \S$ $3^{\circ}$ da Lei o 13.999/2020, onde está especificado que a empresa que solicitar o empréstimo Pronampe deve manter o número de funcionários que possuía na data da publicação da legislação que rege o sistema, até sessenta dias após o recebimento da última parcela do empréstimo, criando-se assim, estabilidade nos contratos de trabalhos dos funcionários que já ocupavam os postos de trabalho na empresa na data da criação da lei.

\section{METODOLOGIA}

Metodologia científica orienta a concepção do processo de investigação, oferecendo diversas alternativas de procedimentos que podem ser adotados para realizar uma pesquisa acadêmica, visto que uma pesquisa científica somente tem validade quando é possível comprovar que os aspectos metodológicos necessários para desenvolvimento da pesquisa foram seguidos (PRODANOV; FREITAS, 2013). Considerando as alternativas de procedimentos subjacentes ao planejamento e execução da pesquisa, pode se afirmar que este estudo possui natureza aplicada, pois seus resultados oferecem a possibilidade de utilização no campo empírico, classifica-se como descritiva e exploratória quantos aos seus objetivos, por coletar e analisar os dados das organizações, sem qualquer alteração ou manipulação dos mesmos, associada à pesquisa bibliográfica e documental, por meio de observação, adotando a estratégia de estudo de casos múltiplos e abordagem qualitativa (ANDRADE, 2010; YIN, 2015).

O estudo de caso é um método de pesquisa muito utilizado em várias áreas do conhecimento, o qual visa dar entendimento ao pesquisador à cerca do fenômeno investigado, este método permite que o pesquisador foque em um, ou 


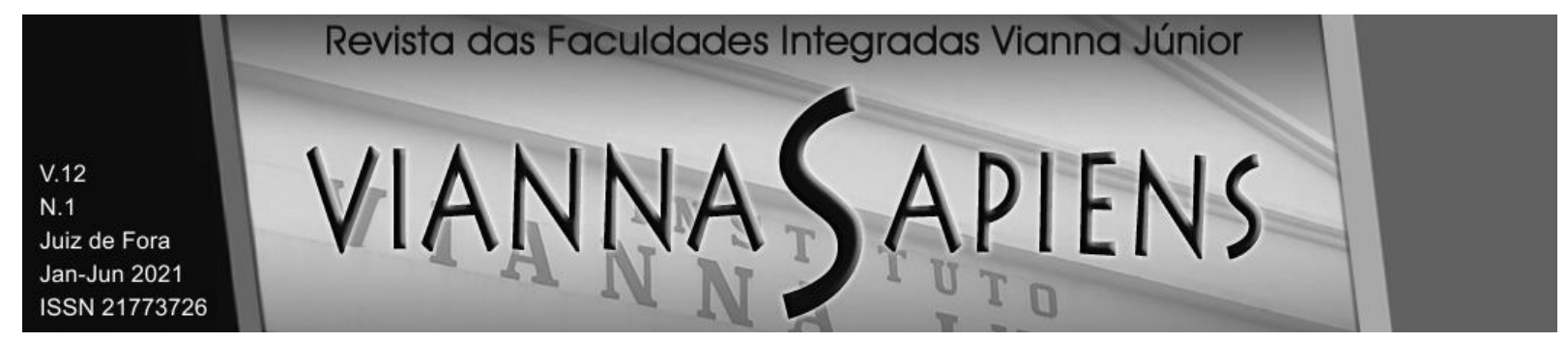

mais casos, em busca dos resultados sobre determinado grupo em estudo. A estrutura metodológica do estudo de casos múltiplos não se distingue da estrutura de um estudo de caso único, a diferença está na unidade de análise, a qual, por ser mais abrangente do que estudo de caso único, pode ser considerada mais robusta (YIN, 2015).

Considerando as recomendações de Mascarenhas (2012), no tocante ao desenvolvimento do estudo, em relação à definição do universo e da amostra, os autores da pesquisa realizaram o estudo com base em banco de dados de 207 Microempresas e Empresas de Pequeno Porte optantes pelo Simples Nacional localizadas na região metropolitana de Porto Alegre - $\mathrm{RS}$, disponibilizado por uma empresa de prestação de serviços contábeis. A coleta de dados também envolveu o levantamento documental em legislações, normas, resoluções e demais informações sobre as medidas de enfrentamento ao COVID-19, bem como em documentos fiscais e demonstrativos disponibilizados pelas empresas participantes do estudo, com o objetivo de verificar os resultados aos objetivos propostos na pesquisa.

Após a coleta de dados, os valores de faturamento, quantidade de funcionários, quantidade de suspensões e reduções foram incluídos em uma planilha, para cálculo da porcentagem de redução ou aumento em cada item de estudo, facultando a verificação de impactos financeiros e econômicos causados pela pandemia de COVID-19 nas micro e pequenas empresas participantes da pesquisa.

A seleção das empresas, a partir do universo das 207 disponibilizadas para consulta, pela empresa de prestação de serviços contábeis, foi realizada por meio da análise da atividade principal desenvolvida. As empresas integrantes da amostra não tiveram sua identidade divulgada, e em razão disso foram nomeadas conforme denominação apresentada no Quadro 1: 


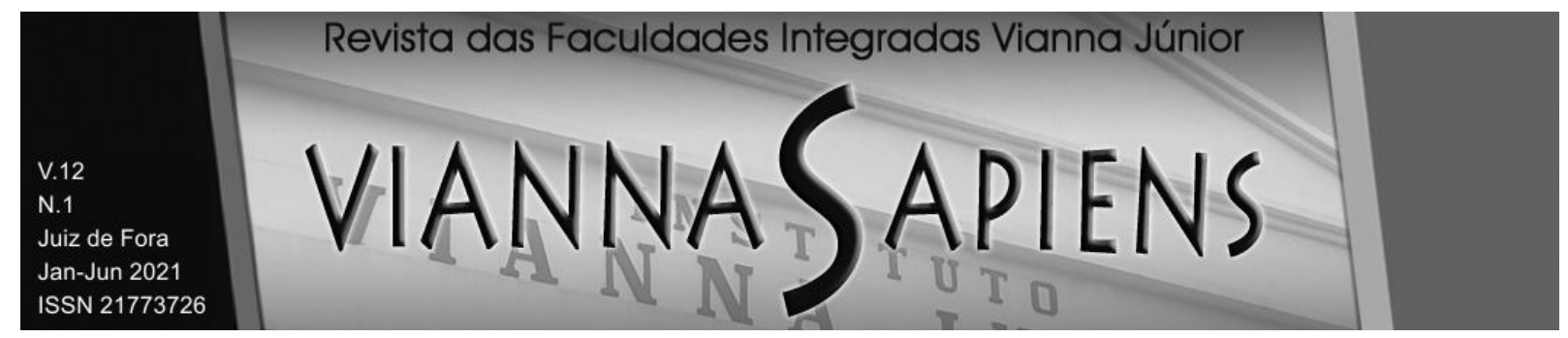

Quadro 1 - Enquadramento das Empresas Integrantes da Amostra

\begin{tabular}{|c|c|c|c|}
\hline Empresa & Porte & Ramo de Atividade & $\begin{array}{l}\text { Anexo Simples } \\
\text { Nacional }\end{array}$ \\
\hline A-I & EPP & Comércio varejista de alimentos & $\mathrm{I}$ \\
\hline A-II & EPP & $\begin{array}{l}\text { Comércio varejista de baterias para veículos } \\
\text { automotores }\end{array}$ & I \\
\hline A-III & ME & $\begin{array}{l}\text { Comércio varejista de artigos e alimentos para } \\
\text { animais de estimação }\end{array}$ & I \\
\hline B-I & $\mathrm{ME}$ & Fabricação/Instalação de máquinas e equipamentos & II e III \\
\hline B-II & EPP & Fabricação/Instalação de máquinas e equipamentos & II e III \\
\hline B-III & ME & $\begin{array}{l}\text { Padaria e confeitaria com predominância de } \\
\text { confecção própria }\end{array}$ & II \\
\hline C-I & EPP & $\begin{array}{l}\text { Serviços de manutenção e reparação } \\
\text { mecânica/Comércio varejista de peças e acessórios }\end{array}$ & I e III \\
\hline C-II & ME & Escola de educação infantil & III \\
\hline C-III & EPP & $\begin{array}{l}\text { Manutenção e reparação de máquinas e } \\
\text { equipamentos }\end{array}$ & III \\
\hline D-I & EPP & Atividades de vigilância e segurança privada & IV \\
\hline D-II & EPP & Atividades de vigilância e segurança privada & IV \\
\hline D-III & ME & Construção de edifícios & IV \\
\hline $\mathrm{E}-\mathrm{I}$ & ME & Atividades de condicionamento físico & V ou III- Fator $\mathrm{R}$ \\
\hline E-II & ME & Gestão e administração da propriedade imobiliária & V ou III- Fator $\mathrm{R}$ \\
\hline E-III & ME & Atividades de condicionamento físico & V ou III- Fator $\mathrm{R}$ \\
\hline F-I & ME & $\begin{array}{l}\text { Representante comercial e agentes do comércio de } \\
\text { madeira, material de construção e ferragens }\end{array}$ & V ou III- Fator $\mathrm{R}$ \\
\hline F-II & ME & Atividade odontológica & V ou III- Fator $\mathrm{R}$ \\
\hline F-III & EPP & Serviços de cartografia, topografia e geodesia & V ou III- Fator $\mathrm{R}$ \\
\hline G-I & EPP & Transporte rodoviário de cargas & III - Transporte \\
\hline G-II & EPP & Transporte rodoviário de cargas & III - Transporte \\
\hline G-III & ME & Transporte rodoviário de cargas & III - Transporte \\
\hline
\end{tabular}

Fonte: Elaborado pelos autores (2020)

No item seguinte estão apresentados os dados analisados de cada empresa participante da pesquisa, conforme amostra apresentada no Quadro 1. A informações expostas nas Tabelas 1 e 2 foram coletadas de forma documental dos setores fiscal, contábil e do departamento pessoal das empresas participantes da pesquisa. 


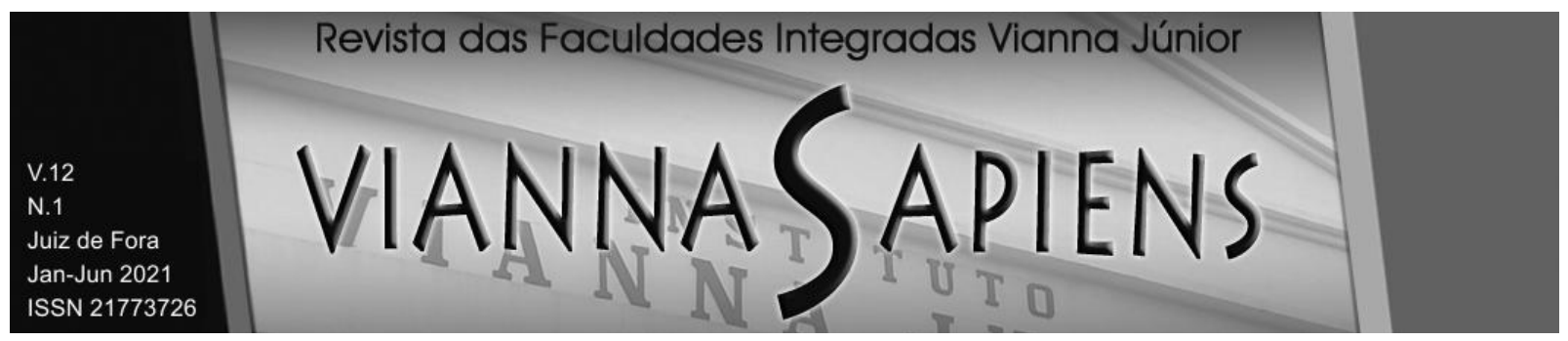

\section{ANÁLISE DOS DADOS}

Para realizar a análise foram investigados os faturamentos das empresas integrantes da amostra e comparados entre a competência março de 2020 , quando iniciaram as orientações para o isolamento social em razão da pandemia de COVID19, e a competência junho de 2020. Também foram observadas as informações dos meses de abril, maio e junho que foram os meses mais impactados pelas medidas governamentais que decretaram os fechamentos de muitas empresas para manter o isolamento social e evitar a disseminação do vírus. Os faturamentos auferidos podem ser verificados na Tabela 1 e o comportamento do número de funcionários na Tabela 2.

Tabela 1 - Redução/Aumento no Faturamento

\begin{tabular}{|c|c|c|c|c|c|c|c|c|c|}
\hline Empresa & & mar/20 & & $a b r / 20$ & & $\mathrm{mai} / 20$ & & jun/20 & $\begin{array}{c}\% \\
\text { aumento/redução }\end{array}$ \\
\hline A-I & $\mathrm{R} \$$ & $258.021,27$ & $\mathrm{R} \$$ & $183.119,00$ & $\mathrm{R} \$$ & $173.218,03$ & $\mathrm{R} \$$ & $192.548,89$ & $-25,3748 \%$ \\
\hline A-II & $\mathrm{R} \$$ & $46.568,00$ & $\mathrm{R} \$$ & $63.080,00$ & $\mathrm{R} \$$ & $57.479,00$ & $\mathrm{R} \$$ & $59.943,00$ & $28,7214 \%$ \\
\hline A-III & $\mathrm{R} \$$ & $6.988,00$ & $\mathrm{R} \$$ & $8.100,00$ & $\mathrm{R} \$$ & $6.779,20$ & $\mathrm{R} \$$ & $4.195,40$ & $-39,9628 \%$ \\
\hline B-I & $\mathrm{R} \$$ & $7.300,00$ & $\mathrm{R} \$$ & $1.850,00$ & $\mathrm{R} \$$ & $2.780,00$ & $\mathrm{R} \$$ & $19.962,80$ & $173,4630 \%$ \\
\hline B-II & $\mathrm{R} \$$ & $170.772,08$ & $\mathrm{R} \$$ & $100.612,12$ & $\mathrm{R} \$$ & $84.068,04$ & $\mathrm{R} \$$ & $64.798,58$ & $-62,0555 \%$ \\
\hline B-III & $\mathrm{R} \$$ & $7.473,61$ & $\mathrm{R} \$$ & $8.112,20$ & $\mathrm{R} \$$ & $8.072,79$ & $\mathrm{R} \$$ & $5.913,10$ & $-20,8803 \%$ \\
\hline $\mathrm{C}-\mathrm{I}$ & $\mathrm{R} \$$ & $55.817,72$ & $\mathrm{R} \$$ & $28.744,29$ & $\mathrm{R} \$$ & $44.860,49$ & $\mathrm{R} \$$ & $47.762,59$ & $-14,4311 \%$ \\
\hline C-II & $\mathrm{R} \$$ & $58.735,00$ & $\mathrm{R} \$$ & $5.448,00$ & $\mathrm{R} \$$ & $15.648,00$ & $\mathrm{R} \$$ & $26.429,40$ & $-55,0023 \%$ \\
\hline C-III & $\mathrm{R} \$$ & $52.114,00$ & $\mathrm{R} \$$ & $31.220,00$ & $\mathrm{R} \$$ & $60.331,00$ & $\mathrm{R} \$$ & $4.110,00$ & $-92,1134 \%$ \\
\hline D-I & $\mathrm{R} \$$ & $49.749,04$ & $\mathrm{R} \$$ & $54.439,57$ & $\mathrm{R} \$$ & $52.289,88$ & $\mathrm{R} \$$ & $52.367,51$ & $5,2634 \%$ \\
\hline D-II & $\mathrm{R} \$$ & $56.686,50$ & $\mathrm{R} \$$ & $37.500,00$ & $\mathrm{R} \$$ & $38.735,00$ & $\mathrm{R} \$$ & $40.350,00$ & $-28,8190 \%$ \\
\hline D-III & $\mathrm{R} \$$ & $16.170,08$ & $\mathrm{R} \$$ & $21.786,13$ & $\mathrm{R} \$$ & $17.737,75$ & $\mathrm{R} \$$ & $17.737,75$ & $9,6949 \%$ \\
\hline E-I & $\mathrm{R} \$$ & $16.286,32$ & $\mathrm{R} \$$ & - & $\mathrm{R} \$$ & $9.527,90$ & $\mathrm{R} \$$ & $2.882,30$ & $-82,3023 \%$ \\
\hline E-II & $\mathrm{R} \$$ & $20.242,08$ & $\mathrm{R} \$$ & $17.700,28$ & $\mathrm{R} \$$ & $19.608,61$ & $\mathrm{R} \$$ & $19.545,15$ & $-3,4430 \%$ \\
\hline E-III & $\mathrm{R} \$$ & $4.850,00$ & $\mathrm{R} \$$ & - & $\mathrm{R} \$$ & - & $\mathrm{R} \$$ & $1.410,00$ & $-70,9278 \%$ \\
\hline F-I & $\mathrm{R} \$$ & $18.197,64$ & $\mathrm{R} \$$ & $12.216,05$ & $\mathrm{R} \$$ & $10.600,21$ & $\mathrm{R} \$$ & $11.365,38$ & $-37,5448 \%$ \\
\hline F-II & $\mathrm{R} \$$ & $5.660,00$ & $\mathrm{R} \$$ & - & $\mathrm{R} \$$ & $2.155,00$ & $\mathrm{R} \$$ & $1.541,68$ & $-72,7618 \%$ \\
\hline F-III & $\mathrm{R} \$$ & $64.886,91$ & $\mathrm{R} \$$ & $70.653,78$ & $\mathrm{R} \$$ & $75.235,17$ & $\mathrm{R} \$$ & $48.723,28$ & $-24,9105 \%$ \\
\hline G-I & $\mathrm{R} \$$ & $57.788,39$ & $\mathrm{R} \$$ & $50.787,95$ & $\mathrm{R} \$$ & $49.001,19$ & $\mathrm{R} \$$ & $42.520,98$ & $-26,4195 \%$ \\
\hline G-II & $\mathrm{R} \$$ & $63.651,07$ & $\mathrm{R} \$$ & $35.649,30$ & $\mathrm{R} \$$ & $35.791,78$ & $\mathrm{R} \$$ & $40.343,37$ & $-36,6179 \%$ \\
\hline
\end{tabular}




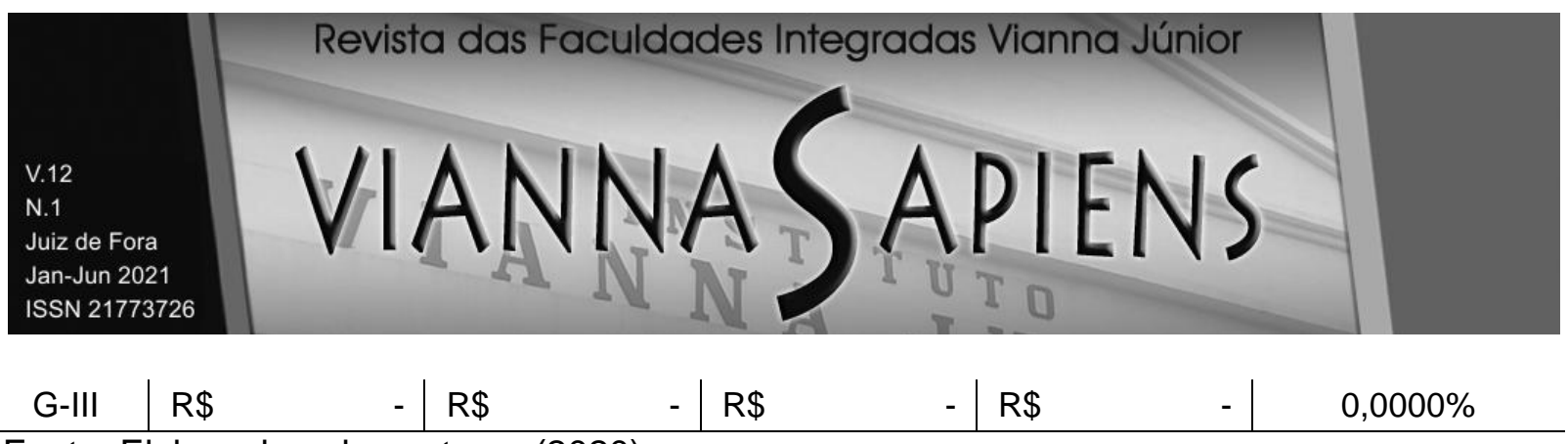

Fonte: Elaborado pelos autores (2020)

A recomendação de isolamento social proposta pela OMS acarretou, diversas vezes, o encerramento das atividades econômicas consideradas não essenciais, causando assim uma restrição no funcionamento de diversas micro e pequenas empresas (CORREIO BRAZILIENSE, 2020). Com o atendimento das referidas recomendações houve impacto no faturamento e no quadro de funcionários das empresas durante o período de pandemia.

Com os dados informados na Tabela 1 é possível constatar que 76,19\% das empresas estudadas tiveram seu faturamento reduzido, 19,05\% apresentaram aumento em seu faturamento e apenas 4,76\% (uma empresa) não tiveram alteração, pois a mesma já estava sem movimento no primeiro mês da pandemia, prevendo o cenário de isolamento social, tendo o contrato com seu cliente suspenso já no início da disseminação do vírus no Brasil.

Tabela 2 - Redução/Aumento no Quadro de Funcionários

\begin{tabular}{|c|c|c|c|c|c|c|}
\hline Empresa & mar/20 & abr/20 & $\mathrm{mai} / 20$ & jun/20 & \% aumento/redução & Suspensão/Redução \\
\hline A-I & 13 & 12 & 12 & 11 & $-15,3846 \%$ & - \\
\hline A-II & 2 & 2 & 2 & 2 & $0,0000 \%$ & - \\
\hline A-III & 1 & 0 & 0 & 0 & $-100,0000 \%$ & - \\
\hline$B-I$ & 1 & 1 & 1 & 1 & $0,0000 \%$ & - \\
\hline B-II & 8 & 5 & 5 & 4 & $-50,0000 \%$ & - \\
\hline B-III & 0 & 0 & 0 & 0 & - & - \\
\hline $\mathrm{C}-\mathrm{I}$ & 5 & 4 & 4 & 4 & $-20,0000 \%$ & \\
\hline C-II & 7 & 7 & 7 & 7 & $0,0000 \%$ & Sim \\
\hline C-III & 3 & 3 & 3 & 3 & $0,0000 \%$ & Sim \\
\hline D-I & 10 & 9 & 8 & 8 & $-20,0000 \%$ & - \\
\hline D-II & 10 & 10 & 9 & 8 & $-20,0000 \%$ & - \\
\hline D-III & 3 & 3 & 3 & 2 & $-33,3333 \%$ & - \\
\hline E-I & 3 & 2 & 2 & 2 & $-33,3333 \%$ & Sim \\
\hline E-II & 7 & 6 & 6 & 6 & $-14,2857 \%$ & - \\
\hline E-III & 2 & 1 & 1 & 1 & $-50,0000 \%$ & Sim \\
\hline $\mathrm{F}-\mathrm{I}$ & 0 & 0 & 0 & 0 & - & - \\
\hline F-II & 0 & 0 & 0 & 0 & - & - \\
\hline F-III & 9 & 9 & 8 & 8 & $-11,1111 \%$ & - \\
\hline G-I & 3 & 3 & 3 & 3 & $0,0000 \%$ & - \\
\hline
\end{tabular}




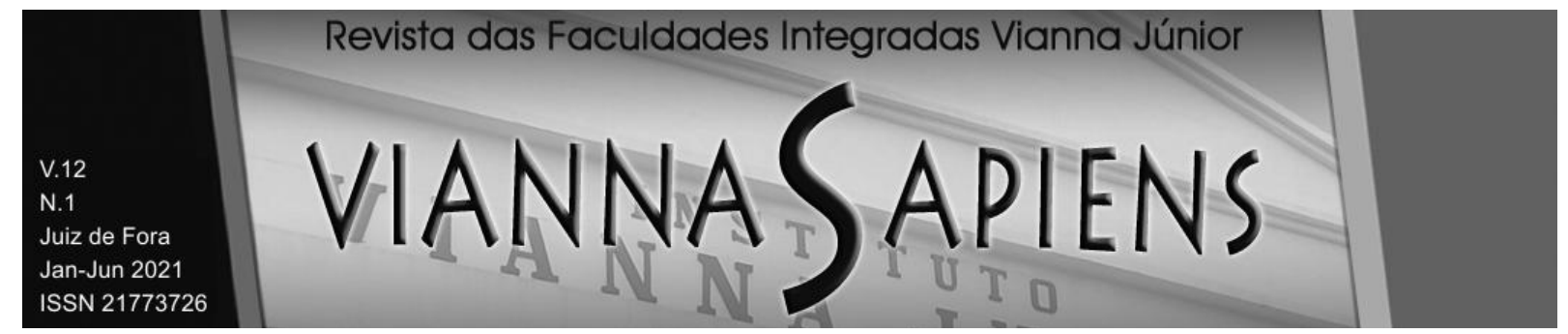

\begin{tabular}{c|c|c|c|c|c|c} 
G-II & 1 & 1 & 1 & 1 & $0,0000 \%$ & - \\
\hline G-III & 0 & 0 & 0 & 0 & - & - \\
\hline
\end{tabular}

Fonte: Elaborado pelos autores (2020)

As empresas que contaram com aumento em suas receitas no período de pandemia foram aquelas que realizam algum tipo de atividade que está sendo, de certa forma, essencial. Uma delas é o comércio varejista de autopeças, que realiza venda para prefeituras, outra empresa é uma metalúrgica que também presta serviço para prefeituras. Esse aumento no faturamento das micro e pequenas empresas que realizam atividade de prestação de serviços ou comercializam bens para órgãos públicos se justifica na medida em que as necessidades na aquisição de bens e serviços até aumentaram no período de calamidade pública para suprir a demanda de atendimentos médicos, construção de hospitais de campanha, entre outras obrigações que surgiram com a pandemia, portanto essas empresas foram beneficiadas pela legislação que dispensou o processo licitatório para órgãos públicos adquirirem bens e serviços necessários para manutenção dos serviços que visam o enfrentamento ao COVID-19, tornando assim o processo de venda mais rápido e eficaz (BRASIL, 2020).

A terceira empresa que obteve aumento em seu faturamento presta serviço de vigilância e monitoramento, atividade demandada em virtude das lojas fechadas e com estoques, suscitando a necessidade de sua proteção contra roubo. A quarta e última empresa que alcançou aumento no faturamento, realiza atividade de construção civil e reparos em edifícios, e que foi contratada para prestar serviço para a prefeitura. Os valores especificados anteriormente podem ser verificados na Tabela 3.

Tabela 3- Redução/Aumento do faturamento

\begin{tabular}{c|c|c|c|c|c}
\hline $\begin{array}{c}\text { Nenhuma } \\
\text { Redução }\end{array}$ & $\begin{array}{c}\text { Redução } \\
\text { entre } \mathbf{0 , 0 1 \%} \\
\mathbf{2 5 \%}\end{array}$ & $\begin{array}{c}\text { Redução } \\
\text { entre } \mathbf{2 6 \%} \\
\mathbf{5 0 \%}\end{array}$ & $\begin{array}{c}\text { Redução } \\
\text { entre 51\% e } \\
\mathbf{7 5 \%}\end{array}$ & $\begin{array}{c}\text { Redução } \\
\text { entre } \mathbf{7 6 \%} \\
\mathbf{1 0 0 \%}\end{array}$ & $\begin{array}{c}\text { Aumento } \\
\text { Faturamento }\end{array}$ \\
\hline 1 empresa & 4 empresas & 6 empresas & 4 empresas & 2 empresas & 4 empresas \\
\hline $4,7619 \%$ & $19,0476 \%$ & $28,5714 \%$ & $19,0476 \%$ & $9,5238 \%$ & $19,0476 \%$ \\
\hline
\end{tabular}

Fonte: Elaborado pelos autores (2020) 


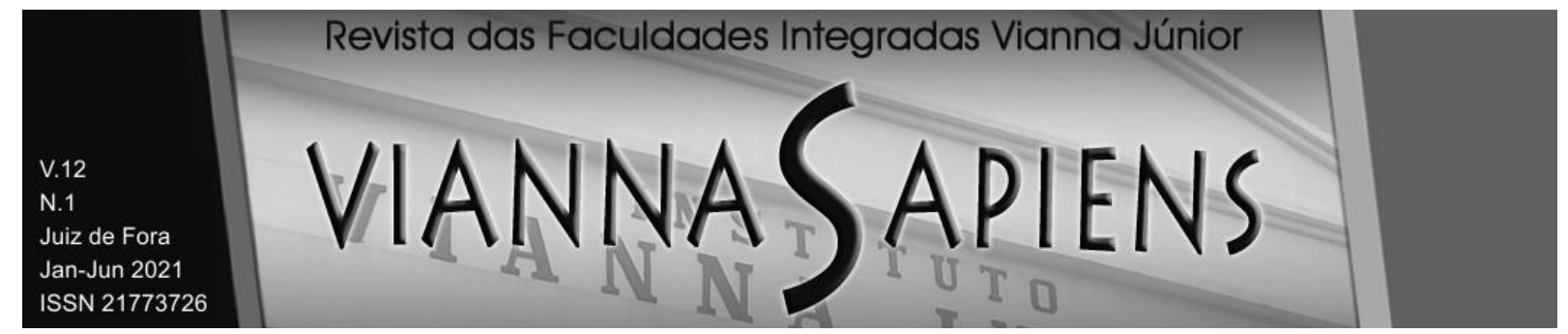

As estruturas organizacionais existentes atualmente baseiam-se na utilização intensiva de pessoas, e no caso das indústrias, ocorrem em linhas de produção, onde a utilização da mão de obra é intensa visando a produtividade máxima, através de uma operação de baixa complexidade, mas, que exige atenção de todas as pessoas envolvidas. Conforme as novas imposições legais essas empresas necessitaram readequar seu estilo de trabalho para evitar a aglomeração de pessoas, assim reduzindo o contágio, e procurando manter a produção (SLACK, 2018).

Conforme os dados informados na Tabela 2 verifica-se que 52,38\% das empresas participantes da pesquisa tiveram alguma redução no seu quadro de funcionários desde o início da pandemia até o último mês analisado, junho de 2020. Já 47,62\% não realizaram nenhuma redução no quadro de funcionários, sendo que 19,05\% destas já não contavam com funcionários ativos no início da pandemia, apenas os sócios desenvolviam as atividades laborais das empresas, sendo assim apenas $28,57 \%$ não necessitaram reduzir o número de funcionários neste período. Estes dados estão demonstrados na Tabela 4.

\section{Tabela 4 - Redução/Suspensão do quadro de funcionários}

\begin{tabular}{|c|c|c|c|c|c|}
\hline $\begin{array}{l}\text { Nenhuma } \\
\text { Redução }\end{array}$ & $\begin{array}{c}\text { Redução entre } \\
0,01 \% \text { e } 25 \%\end{array}$ & $\begin{array}{c}\text { Redução entre } \\
26 \% \text { e } 50 \%\end{array}$ & $\begin{array}{c}\text { Redução entre } \\
51 \% \text { e } 75 \%\end{array}$ & $\begin{array}{c}\text { Redução entre } \\
76 \% \text { e } 100 \%\end{array}$ & $\begin{array}{c}\text { Suspensão/ } \\
\text { Redução }\end{array}$ \\
\hline 10 empresas & 6 empresas & 4 empresas & - & 1 empresa & 4 empresas \\
\hline $47,6190 \%$ & $28,5714 \%$ & $19,0476 \%$ & $0,0000 \%$ & $4,7619 \%$ & $19,0476 \%$ \\
\hline
\end{tabular}

Fonte: Elaborado pelos autores (2020)

De todas as empresas analisadas somente 19,05\% utilizaram os benefícios de redução e suspensão concedidos pela Lei no 14.020/2020, no entanto todas se utilizaram dos benefícios da MP nº 927/2020, realizando antecipação de férias no mês de março e prorrogação do pagamento do FGTS deste período. Somente $14,29 \%$ das empresas tiveram condições de operar através do teletrabalho. Uma delas, uma escola de educação infantil, seguiu com as operações de ensino através de vídeo conferência e duas academias de condicionamento físico realizaram as aulas também por vídeo conferência. 


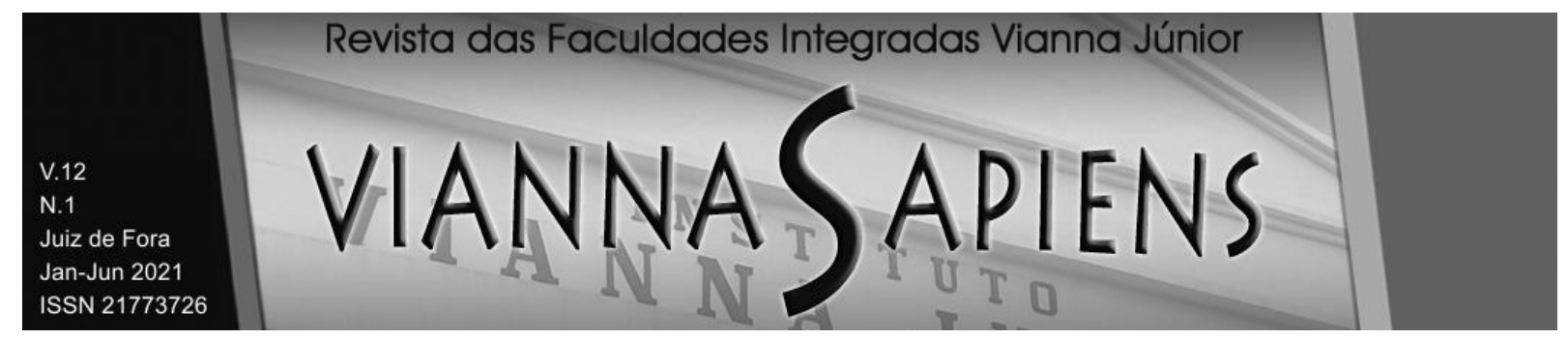

Todas as empresas participantes da pesquisa utilizaram-se da prorrogação do vencimento do DAS dos meses de março, abril e maio concedidas pela Resolução CGSN nำ154/2020, em razão de buscarem manter um fluxo de caixa positivo e criar capital de giro, visto que antes da pandemia algumas empresas não tinham como praxe manter valor disponível, operando no seu limite financeiro. Com essas concessões de prorrogações todas empresas puderam deixar um valor em seus caixas, mesmo que momentaneamente (SOBRAL; CARDOSO; SANCHES, 2017).

Conforme os dados apresentados nas Tabelas 1 e 2 constatou-se que as micro e pequenas empresas que foram mais atingidas pelas crise financeira são as academias, que desenvolvem atividades de condicionamento físico, as prestadoras de serviço nas atividades de ensino e uma prestadora de serviço que realiza locação de equipamentos e manutenção, que tiveram seus faturamentos reduzidos e utilizaram a suspensão para não realizar a demissão dos funcionários, já que suas atividades não são consideradas essenciais.

\section{CONSIDERAÇÕES FINAIS}

As micro e pequenas empresas são essenciais para a economia nacional, visto que elas garantem a maior geração de empregos e renda para os brasileiros nos últimos anos, razão pela qual possuem seu próprio estatuto, o qual garante tratamento diferenciado e estímulos para que os pequenos negócios cresçam continuamente e permaneçam impulsionando a economia do país.

Para o desenvolvimento deste estudo foi realizada, inicialmente, pesquisa bibliográfica em livros, artigos, revistas e na legislação a fim de averiguar a importâncias das micro e pequenas empresas e sua representatividade na economia nacional, bem como seu tratamento diferenciado. Na segunda etapa realizou-se coleta documental dos setores fiscal, contábil e do departamento pessoal das empresas integrantes da amostra para obter os dados de faturamento, folha de 


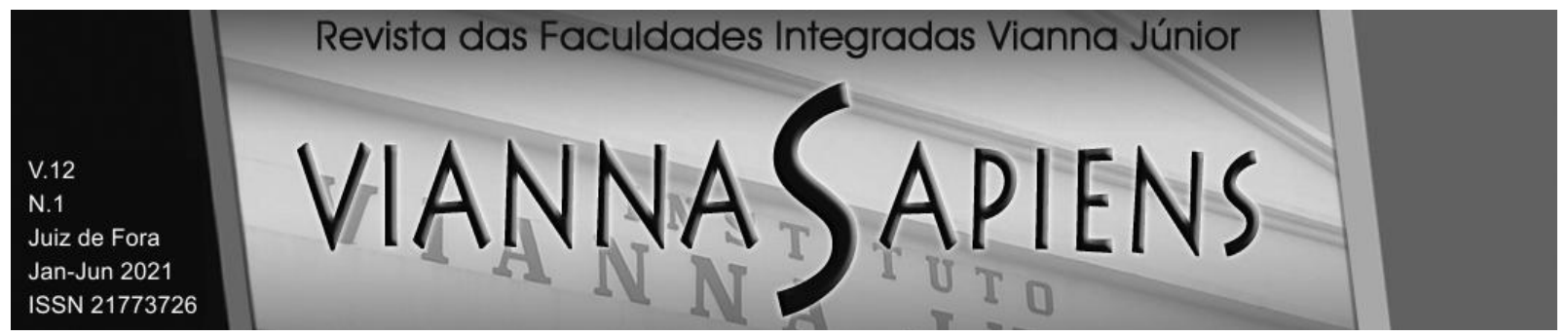

pagamento, número de funcionários, quantidade de reduções e suspensões, e outras informações necessárias.

A análise dos dados realizada facultou a identificação de informações empíricas disponibilizados pelas empresas, assim como legislações, documentos fiscais e informações obtidas no sistema de gestão contábil. Os objetivos da pesquisa foram alcançados visto que foi possível verificar a oscilação no faturamento das empresas no período de pandemia, quais atividades foram mais atingidas e a quantidade de empresas que optaram por reduzir o quadro de funcionários ou utilizar da redução e suspensão liberada pelo governo federal.

Através da pesquisa foi possível verificar que dez empresas estudadas não realizaram nenhuma redução em seu quadro de funcionários, sendo que quatro já não contavam com funcionários no início da pandemia, apenas quatro realizaram suspensão e redução do quadro de funcionários, e, onze empresas realizaram demissões durante a pandemia, destas onze, duas das que utilizaram a suspensão instituída pela Lei no 14.020/2020, acabaram também reduzindo o número de funcionários. Apenas uma empresa não sofreu redução em seu faturamento, e as quatro empresas que auferiram aumento de receita se beneficiaram por vender/prestar serviços para prefeituras, às quais estão com grande demanda em razão do estado de calamidade pública na área da saúde.

Dezesseis empresas sofreram com redução em seus faturamentos mensais, dessas, duas são atividades de comércio varejista, minimercados, que ficaram abertos por ser atividade essencial, duas indústrias e as demais prestadoras de serviços diversos. Pode-se concluir que a pandemia de COVID-19 impactou diretamente na existência atual e na continuidade futura das operações das micro e pequenas empresas, visto que, através dos dados estudados, foi observado que a maioria contou com redução no faturamento e no quadro de funcionários nestes quatro primeiros meses de isolamento social. Desta forma, pode-se concluir que as medidas governamentais adotadas pelas micro e pequenas empresas estão as auxiliando a manter os empregos durante a pandemia e honrar com seus 


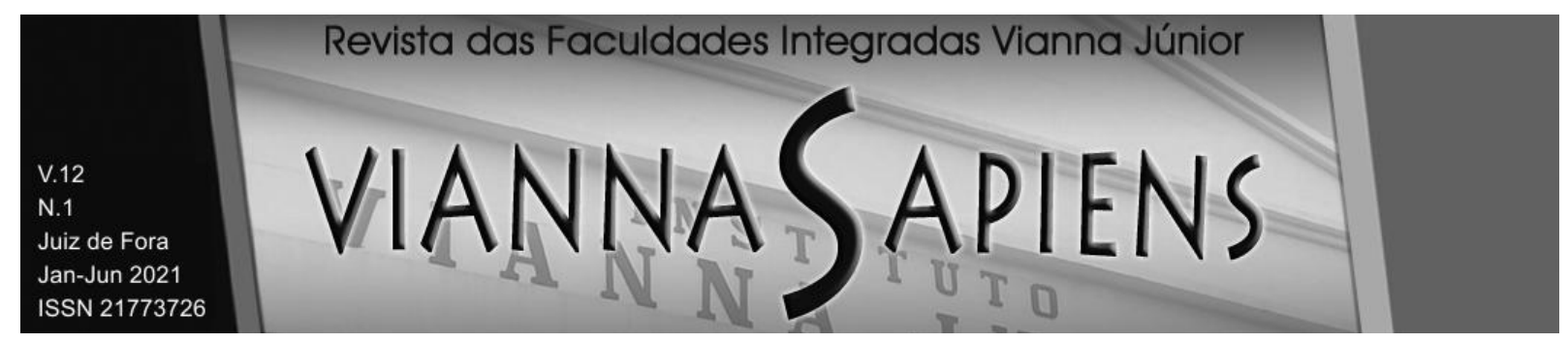

compromissos financeiros, através da redução e suspensão dos funcionários e, da prorrogação no pagamento de alguns tributos.

$O$ aumento de preços para recuperação de receita justamente quando se prevê o encerramento de milhares de empresas, de micro e de pequeno porte, não parece ser um cenário viável, neste momento, no contexto pandêmico. $O$ cenário que se mostra como mais provável, ao menos, por ora, é o do reinício das operações, com vistas à sua continuidade, com adequação de estruturas de funcionamento para atender as determinações legais, com o intuito primordial de gerar o caixa e honrar os compromissos assumidos, deixando para o segundo momento a consolidação de registros contábeis, com a consequente análise da viabilidade (ou não) da manutenção da operação, considerando os ajustes estruturais exigidos.

E desta forma, os profissionais da área contábil, com expertise em gestão de custos, poderão oferecer contribuições relevantes para apoiar o empreendedor no processo de revisão do seu modelo de negócios. De forma similar, os especialistas em gestão de operações, poderão contribuir para o redesenho de processos, bem como sugerir alternativas para a adoção de tecnologias no âmbito da indústria 4.0. Já os experts em marketing deverão facultar na digitalização do negócio, respeitando suas características, é claro, bem como abrir os canais para a comunicação com os consumidores, por meio de redes sociais.

À guisa de conclusão, é possível afirmar que o mundo pós pandemia será diferente do mundo que existia anteriormente. Nem todas as mudanças são possíveis antever neste momento e tampouco a repercussão das mesmas nas vidas das pessoas e das organizações, mas provavelmente serão mudanças que marcarão todos de forma permanente, com reduzidas chances de retorno ao formato pré pandemia. Sugere-se a continuidade de estudos sobre o assunto, visto que a pandemia de COVID-19 está mudando os paradigmas da sociedade como um todo, ademais nesta pesquisa foram analisados os impactos financeiros e econômicos apenas nos quatro primeiros meses da pandemia, é importante investigar o 


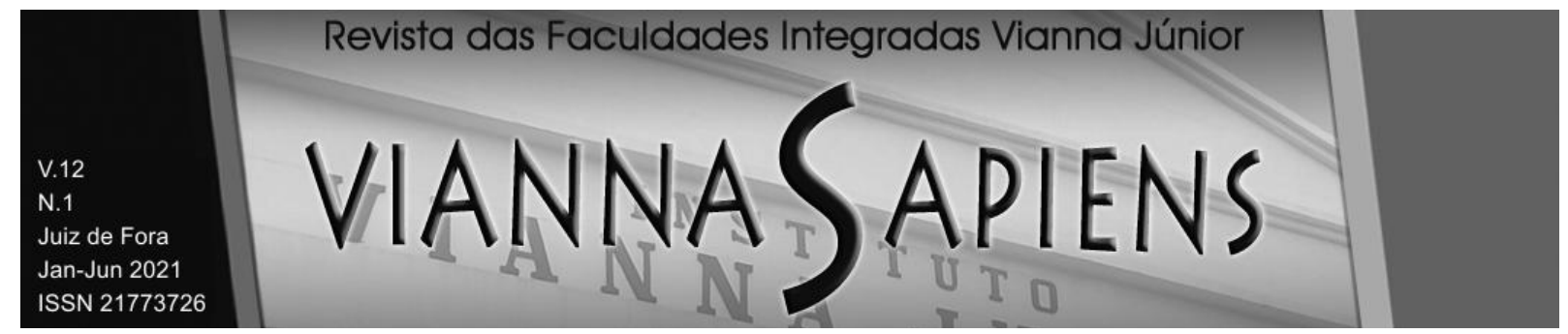

comportamento das micro e pequenas empresas até o final do ano de 2020 e no período pós-pandemia.

\section{REFERÊNCIAS}

ANDRADE, Maria Margarida de. Introdução à Metodologia do Trabalho

Científico: elaboração de Trabalhos na Graduação. 10. ed. São Paulo, SP: Atlas, 2010.

BOTELHO; Delane; GUISSONI, Leandro. Varejo: competitividade e Inovação.

Revista de Administração de Empresas. Vol.56, № 6, São Paulo, Nov/ Dez 2016.

BRASIL. Constituição da República Federativa do Brasil de 1988. Brasília. Disponível em: <http://www.planalto.gov.br/ccivil_03/Constituicao/Constituicao.htm>. Acesso em 26 jul. 2020.

. Lei no 123, de 14 de dezembro de 2006. Institui o Estatuto Nacional da Microempresa e da Empresa de Pequeno Porte; altera dispositivos das Leis n- 8.212 e 8.213, ambas de 24 de Julho de 1991, da Consolidação das Leis do Trabalho CLT. Disponível em: <http://www.planalto.gov.br/ccivil_03/leis/LCP/Lcp123.htm>. Acesso em 25 jul. 2020.

Lei no 155, de 27 de outubro de 2016. Altera a Lei Complementar nํ 123, de 14 de Dezembro de 2006, para reorganizar e simplificar a metodologia de apuração do imposto devido por optantes pelo Simples Nacional; altera as Leis nํㅗ 9.613, de 3 de Março de 1998, 12.512, de 14 de Outubro de 2011, e 7.998, de 11 de Janeiro de 1990; e revoga o dispositivo da Lei no 8.212, de 24 de Julho de 1991.

Disponível em: < http://www.planalto.gov.br/ccivil_03/leis/LCP/Lcp155.htm > Acesso em 24 jul. 2020.

Lei 13.467 de 13 de julho de 2017.Altera a Consolidação das Leis do Trabalho (CLT), aprovada pelo Decreto-Lei no 5.452, de 1ำ de maio de 1943, e as Leis n-6.019, de 3 de janeiro de 1974, 8.036, de11 de maio de 1990, e 8.212, de 24 de julho de 1991, a fim de adequar a legislação às novas relações de trabalho.Disponível em: <http://www.planalto.gov.br/ccivil_03/_ato20152018/2017/lei//13467.htm>. Acesso em 12 mai. 2020. 


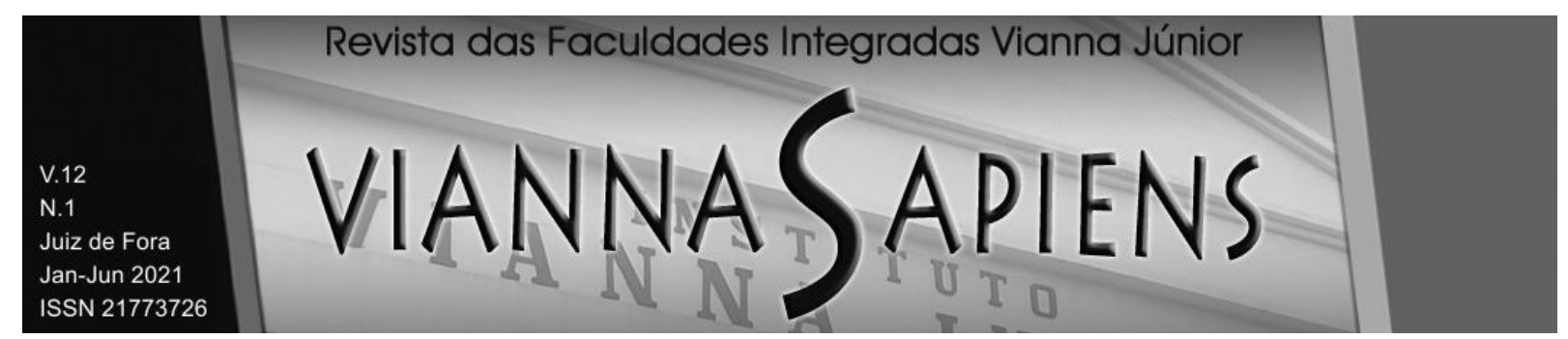

Lei no 13.979, de 06 de fevereiro de 2020. Dispõe sobre as medidas para enfrentamento da emergência de saúde pública de importância internacional decorrente do coronavírus responsável pelo surto de 2019 . Brasília, 06 fev. 2020. Disponível em: <http://www.planalto.gov.br/ccivil_03/_ato20192022/2020/lei//13979.htm>. Acesso em: 20 jul. $20 \overline{20}$.

Lei no 13.999, de 18 de maio de 2020. Institui o Programa Nacional de Apoio às Microempresas e Empresas de Pequeno Porte (Pronampe), para o desenvolvimento e o fortalecimento dos pequenos negócios; e altera as Leis nos 13.636, de 20 de março de 2018, 10.735, de 11 de setembro de 2003, e 9.790, de 23 de março de 1999. Brasília, 18 maio 2020. Disponível em:

<http://www.planalto.gov.br/ccivil_03/_ato2019-2022/2020/Lei/L13999.htm>. Acesso em: 20 jul. 2020.

. Lei no 14020, de 06 de julho de 2020. Institui o Programa Emergencial de Manutenção do Emprego e da Renda; dispõe sobre medidas complementares para enfrentamento do estado de calamidade pública reconhecido pelo Decreto Legislativo $\mathrm{n}^{\circ} 6$, de 20 de março de 2020, e da emergência de saúde pública de importância internacional decorrente do coronavírus, de que trata a Lei no 13.979, de 6 de fevereiro de 2020; altera as Leis nos 8.213, de 24 de julho de 1991, 10.101, de 19 de dezembro de 2000, 12.546, de 14 de dezembro de 2011, 10.865, de 30 de abril de 2004, e 8.177, de 1ำ de março de 1991; e dá outras providências. Brasília, 06 jul. 2020. Disponível em: <http://www.planalto.gov.br/ccivil_03/_ato20192022/2020/Lei/L14020.htm>. Acesso em: 20 jul. 2020.

Medida Provisória 927 de 22 de março de 2020.Dispõe sobre as medidas trabalhistas para enfrentamento do estado de calamidade pública reconhecido pelo Decreto Legislativo ํㅜ 6, de 20 de março de 2020 e da emergência de saúde pública de importância internacional decorrente do coronavírus (covid-19), e dá outras providências.Disponível em: <http://www.planalto.gov.br/ccivil_03/_ato20192022/2020/Mpv/mpv927.htm>.Acesso em 15 mai. 2020.

Medida Provisória 936 de 1ำ de Abril de 2020. Institui o Programa Emergencial de Manutenção do Emprego e da Renda e dispõe sobre medidas trabalhistas complementares para enfrentamento do estado de calamidade pública reconhecido pelo Decreto Legislativo n 6 , de 20 de março de 2020, e da emergência de saúde pública de importância internacional decorrente do coronavírus (covid-19), de que trata a Lei no 13.979, de 6 de fevereiro de 2020, e dá outras providências.Disponível em: <http://www.planalto.gov.br/ccivil_03/_Ato20192022/2020/Mpv/mpv936.htm>. Acesso em 15 mai. 2020. 


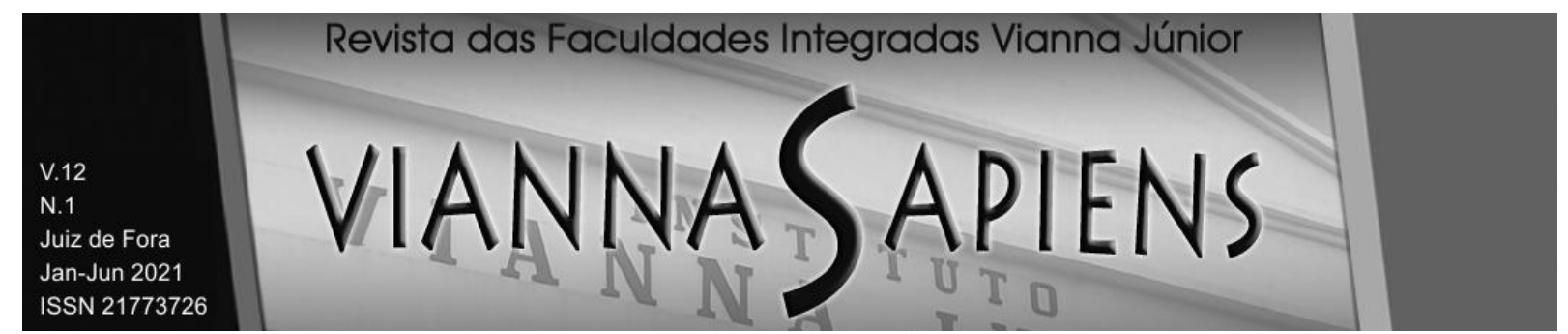

Medida Provisória no 944, de 03 de abril de 2020. Institui o Programa Emergencial de Suporte a Empregos. Brasília, 03 abr. 2020. Disponível em: <http://www.planalto.gov.br/ccivil_03/_ato2019-2022/2020/Mpv/mpv944.htm>. Acesso em: 20 jul. 2020.

. Ministério da Economia: Governo lança Programa Emergencial de Manutenção do Emprego para Enfrentar Efeitos Econômicos da COVID19.Disponível em: <http://trabalho.gov.br/noticias/7373-governo-lanca-programaemergencial-de-manutencao-do-emprego-para-enfrentar-efeitos-economicos-dacovid-19>. Acesso em 16 jun. 2020.

Ministério da Saúde. Coronavírus Covid-19. Brasília, DF, 2020. Disponível em: <https://coronavirus.saude.gov.br/>. Acesso em 3 de mai. 2020.

Resolução CGSN no 154 de 03 de abril de 2020.Dispõe sobre a prorrogação de prazos de pagamento de tributos no âmbito do Simples Nacional, em razão da pandemia da Covid-19.Disponível em:

$<$ http://normas.receita.fazenda.gov.br/sijut2consulta/link.action?visao=anotado\&idAto $=10836>8$. Acesso em 15 mai. 2020 .

BRUNI, Adriano Leal. Administração custos preços lucros. 6. Rio de Janeiro Atlas 2018.

CORREIO BRAZILIENSE. OMS reforça proposta de isolamento social contra coronavírus. Correio Braziliense, 2020. Disponível em:

https://www.correiobraziliense.com.br/app/noticia/mundo/2020/03/26/interna_mundo, 839962/oms-reforca-proposta-de-isolamento-social-contra-coronavirus.shtml.

Acesso em: 26 mar. 2020.

COSTA, Aline Pereira Neves da; LEANDRO, Luiz Alberto de Lima. O atual cenário das micro e pequenas empresas no Brasil. 13. ed. Resende: Aedb, 2016. Disponível em: <https://www.aedb.br/seget/arquivos/artigos16/14924134.pdf>. Acesso em: 26 jul. 2020.

DORNELAS, José. Empreendedorismo transformando ideias em negócios. 7.ed. São Paulo Fazendo Acontecer 2018. 


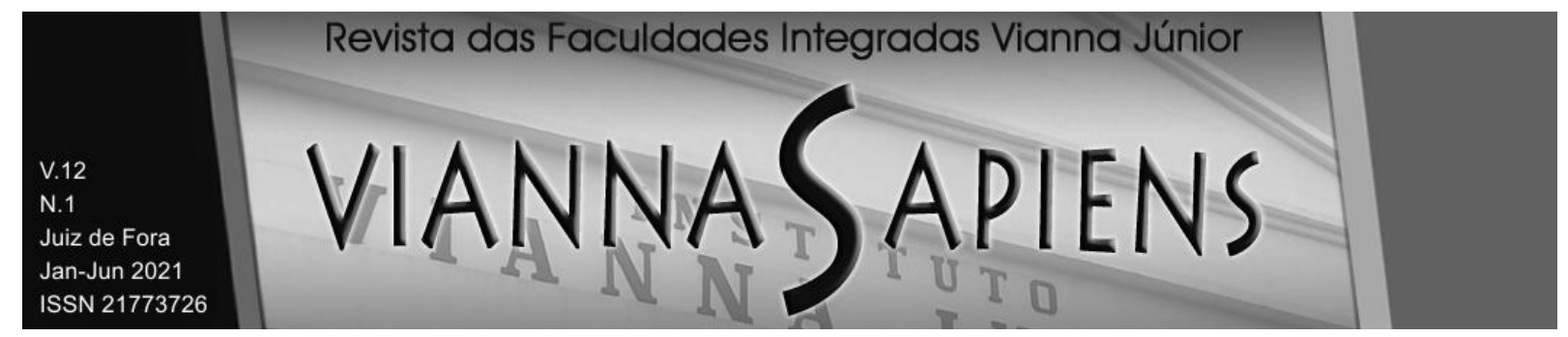

BARBOSA FILHO, Fernando de Holanda. A crise econômica de 2014/2017. Estudos Avançados. 31 (89), 2017.

FREITAS, André Ricardo Ribas; NAPIMOGA, Marcelo; DONALISIO, Maria Rita. Análise da gravidade da pandemia de Covid-19. Epidemiol. Serv. Saúde, Brasília, v. 29, n. 2, e2020119, 2020.

HIGUCHI, Hiromi. Imposto de Renda das Empresas: interpretação e prática atualizado até 15/02/2017. São Paulo: Crc, 2017. Disponível em: <http://www.crcsp.org.br/portal/publicacoes/livros/imposto-de-renda-dasempresas.pdf> Acesso em: 24 de jul. 2020.

MARTINS, Gilberto de Andrade. Estudo de caso: uma estratégia de pesquisa. São Paulo, SP: Atlas, 2006.

MASCARENHAS, Sidnei Augusto. Metodologia Científica. São Paulo: Pearson Education do Brasil, 2012.

PÊGAS, Paulo Henrique. Manual de Contabilidade Tributária. 8. ed. Rio de Janeiro: Freitas Bastos, 2014. 844 p.

PESSÔA, Leonel Cesarino; COSTA, Giovane da; MACCARI, Emerson Antonio. As micro e pequenas empresas, o SimplesNacional e o problema dos créditos de ICMS. 12. ed. São Paulo: Revista Direito Fgv, 2015. ISSN 2317-6172. Disponível em: <https://www.scielo.br/pdf/rdgv/v12n2/1808-2432-rdgv-12-2-0345.pdf>. Acesso em: 23 jul. 2020.

PORTO ALEGRE - RS (Município). Decreto № 20.534, de 31 de Março de 2020. Decreta o estado de calamidade pública e consolida as medidas para enfrentamento da emergência de saúde pública de importância internacional decorrente do novo Coronavírus (COVID-19), no Município de Porto Alegre. Disponível em: <https://leismunicipais.com.br/a/rs/p/porto-alegre/decreto/2020/2053/20534/decreton-20534-2020-decreta-o-estado-de-calamidade-publica-e-consolida-as-medidaspara-enfrentamento-da-emergencia-de-saude-publica-de-importancia-internacionaldecorrente-do-novo-coronavirus-covid-19-no-municipio-de-porto-alegres. Acesso em: 23 jul. 2020. 


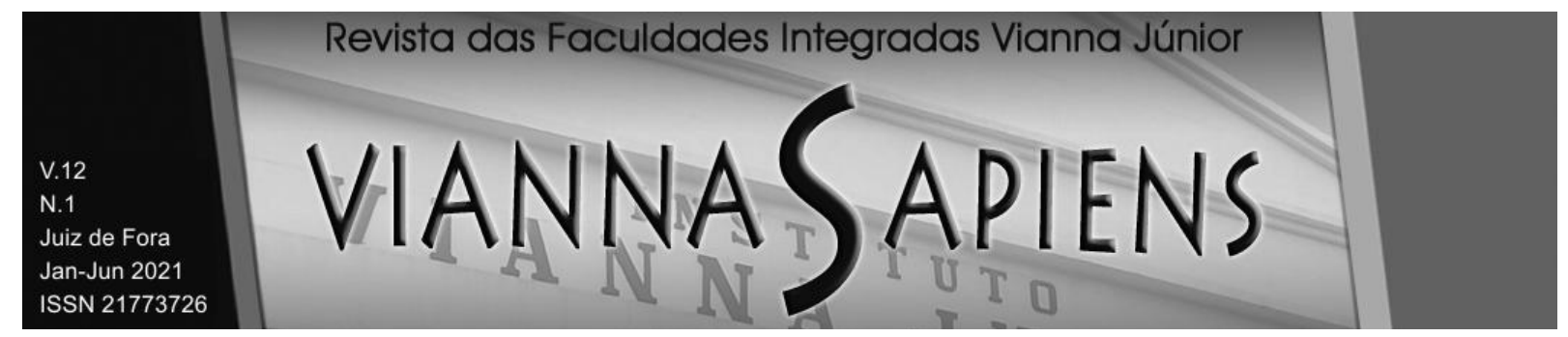

PRODANOV, Cleber Cristiano; FREITAS, Ernani Cesar de. Metodologia do trabalho científico: métodos e técnicas da pesquisa e do trabalho acadêmico. 2. ed. Novo Hamburgo, RS: Feevale, 2013. 276 p. ISBN 9788577171583 Disponível em: < http://www.feevale.br/Comum/midias/8807f05a-14d0-4d5b-b1ad1538f3aef538/E-book\%20Metodologia\%20do\%20Trabalho\%20Cientifico.pdf> Acesso em 24 jul. 2020.

REZENDE, Amaury José; PEREIRA, Carlos Alberto; ALENCAR, Roberta Carvalho de. Contabilidade tributária: entendendo a lógica dos tributos e seus reflexos sobre os resultados das empresas. São Paulo: Atlas, 2010.

RIO GRANDE DO SUL (Estado). Assembleia Legislativa Lei no 15.057, de 27 de dezembro de 2017. Altera a Lei n. -13.036 , de 19 de setembro de 2008, que institui benefícios aplicáveis às empresas estabelecidas no Estado e enquadradas no Regime Especial Unificado de Arrecadação de Tributos e Contribuições devidos pelas Microempresas e Empresas de Pequeno Porte - Simples Nacional. Porto Alegre, RS. Disponível em:

<http://www.al.rs.gov.br/filerepository/repLegis/arquivos/LEl\%2015.057.pdf> Acesso em 26 jul. 2020.

SEBRAE: Especialista em Pequenos Negócios. Disponível em: <http://www.agenciasebrae.com.br/asn/Indicadores/Novo\%20MPE\%20Indicadores\% 20-\%20\%2001\%2010\%202019.pdf:. Acesso em: 13 mai. 2020.

Impactos e tendências da COVID-19 nos pequenos negócios.

Disponível em: <https://www.sebrae.com.br/sites/PortalSebrae/artigos/impactos-etendencias-da-covid-19-nos-pequenos-

negocios,5e8fbd0c7d711710VgnVCM1000004c00210aRCRD > Acesso em 02 de mai. 2020.

Geração de empregos pelos pequenos negócios revela melhor agosto em cinco anos. 2019. Disponível em: $<$ http://www.agenciasebrae.com.br/sites/asn/uf/NA/geracao-de-empregos-pelospequenos-negocios-revela-melhor-agosto-em-cincoanos, 0110b11fbef6d610VgnVCM1000004c00210aRCRD\#: :text=Gera\%C3\%A7\%C 3\%A30\%20de\%20empregos\%20pelos\%20pequenos\%20neg\%C3\%B3cios\%20revel a\%20melhor\%20agosto\%20em\%20cinco\%20anos,-

Levantamento\%20feito\%20pelo\&text=\%E2\%80\%9COs\%20pequenos\%20neg\%C3\% B3cios\%2C\%20que\%20hoje,levantamentos\%20do\%20Minist\%C3\%A9rio\%20da\%20 Economia.> Acesso em 23 jul. 2020. 


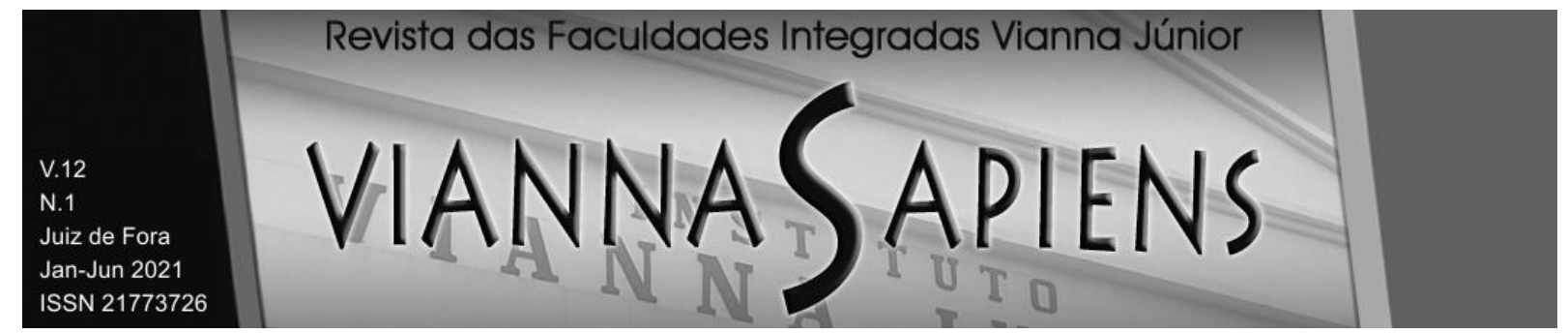

Mato Grosso. Simples Nacional: mudanças para 2018. 2018. Disponível

em:

<https://m.sebrae.com.br/Sebrae/Portal\%20Sebrae/UFs/AM/Banner/arquivo_151248

1714.pdf> Acesso em 27 jul. 2020.

Pequenos negócios sustentam geração de empregos no país, mostra pesquisa. 2019. Disponível em:

<https://revistapegn.globo.com/Noticias/noticia/2019/03/pequenos-negocios-

sustentam-geracao-de-empregos-no-pais-mostra-pesquisa.html> Acesso em 23 jul. 2020.

SILVA, Lourivaldo Lopes da. Contabilidade geral e tributária. 7. ed. São Paulo: lob, 2012.

SLACK, Nigel. Administração da produção. 8. Rio de Janeiro Atlas 2018

SOBRAL, José de Arimatéia; CARDOSO, Rosane Carvalho; SANCHES, Graziele Aline Feitosa. A gestão do capital de giro das micro e pequenas empresas.

Birigui: Fateb Científica, 2017. ISSN 2594-9438. Disponível em:

<http://www.fateb.br/fateb.cientifica/downloads/1a_edicao/artigos/004_a_gestao_do_ capital_de_giro_das_micro_e_pequenas_empresas.pdf>. Acesso em: 23 jul. 2020.

YIN, Robert K. Estudo de caso: planejamento e métodos. 5. ed. Porto Alegre: Bookman, 2015.

Recebido em 04/09/2020

Publicado em 23/02/2021 